\title{
Evolving role of neurokinin I-receptor antagonists for chemotherapy-induced nausea and vomiting
}

This article was published in the following Dove Press journal: OncoTargets and Therapy

\section{Rudolph M Navari' \\ Lee S Schwartzberg ${ }^{2}$}

'Department of Hematology/ Oncology, University of Alabama at Birmingham, Birmingham, AL, USA; ${ }^{2}$ Division of Hematology/Oncology, Department of Medicine, University of Tennessee Health Science Center and West Cancer Center, Memphis, TN, USA
Correspondence: Rudolph M Navari University of Alabama at Birmingham, North Pavilion 2540K, 1802 Sixth Avenue, Birmingham, AL 35294, USA

Tel +l 2059752833

Fax +I 2059753910

Email rnavari@uabmc.edu

\begin{abstract}
To examine pharmacologic and clinical characteristics of neurokinin $1\left(\mathrm{NK}_{1}\right)$-receptor antagonists (RAs) for preventing chemotherapy-induced nausea and vomiting (CINV) following highly or moderately emetogenic chemotherapy, a literature search was performed for clinical studies in patients at risk of CINV with any approved $\mathrm{NK}_{1}$ RAs in the title or abstract: aprepitant (capsules or oral suspension), HTX019 (intravenous [IV] aprepitant), fosaprepitant (IV aprepitant prodrug), rolapitant (tablets or IV), and fixed-dose tablets combining netupitant or fosnetupitant (IV netupitant prodrug) with the 5-hydroxytryptamine type $3\left(5 \mathrm{HT}_{3}\right)$ RA palonosetron (oral or IV). All $\mathrm{NK}_{1}$ RAs are effective, but exhibit important differences in efficacy against acute and delayed CINV. The magnitude of benefit of NK - RA-containing three-drug vs twodrug regimens is greater for delayed vs acute CINV. Oral rolapitant has the longest half-life of available $\mathrm{NK}_{1}$ RAs, but as a consequence should not be administered more frequently than every 2 weeks. In general, $\mathrm{NK}_{1}$ RAs are well tolerated; however, IV rolapitant was recently removed from US distribution, due to hypersensitivity and anaphylaxis, and IV fosaprepitant is associated with infusion-site reactions and hypersensitivity presumed related to its polysorbate 80 excipient. Also, available $\mathrm{NK}_{1}$ RAs have potential drug-drug interactions. Adding an $\mathrm{NK}_{1}$ $\mathrm{RA}$ to $5 \mathrm{HT}_{3} \mathrm{RA}$ and dexamethasone significantly improves CINV control vs the two-drug regimen. Newer $\mathrm{NK}_{1}$ RAs offer more formulation options, higher acute-phase plasma levels, or improved tolerability, and increase clinicians' opportunities to maximize benefits of this important class of antiemetics.
\end{abstract}

Keywords: aprepitant, chemotherapy-induced nausea and vomiting, fosaprepitant, netupitant, neurokinin 1-receptor antagonists, rolapitant

\section{Plain-language summary}

This review aims to evaluate the unmet need for superior control of a common side effect of chemotherapy, known as chemotherapy-induced nausea and vomiting (CINV). Prevention of CINV maintains the patient's quality of life and minimizes CINV-related hospital visits. Several guidelines exist that recommend specific drug regimens for CINV treatment. One class of drugs recommended to prevent CINV, known as neurokinin 1-receptor antagonists ( $\mathrm{NK}_{1}$ RAs), is underused in clinical practice. Several $\mathrm{NK}_{1}$ RAs are available, which have pharmacologic and clinical differences including formulation (intravenous vs oral), efficacy, and safety profiles. These differences should guide a physician's choice of treatment for each patient. An $\mathrm{NK}_{1} \mathrm{RA}$ can be added to an antiemetic regimen, a combination of drugs for preventing nausea and vomiting that includes a 5-hydroxytryptamine type 3 RA and corticosteroid. This regimen can significantly reduce episodes of vomiting and the need for additional medications. However, nausea control remains suboptimal, and further research is needed to find better antiemetic regimens to prevent vomiting and nausea successfully, specifically CINV. Some of the newer, improved $\mathrm{NK}_{1}$ RAs can add maximum benefit to the antiemetic-drug regimen. 


\section{Introduction}

Nausea and vomiting (NV) are common, distressing adverse effects of chemotherapy. ${ }^{1,2}$ Chemotherapy-induced NV (CINV) significantly affects patients' daily functioning, ${ }^{2-4}$ quality of life, ${ }^{1,5-8}$ and ability to eat. ${ }^{2,6}$ Patients with uncontrolled CINV require more health care resources and incur greater health care costs. ${ }^{3,8-10}$ Poorly controlled or severe CINV can prompt a chemotherapy dose reduction or cycle delay, ${ }^{11}$ ultimately affecting chemotherapy outcomes.

CINV incidence depends on several factors, including female sex, ${ }^{12}$ young age $\left(<50\right.$ years) ${ }^{13,14}$ and anxiety,,${ }^{15}$ but the key determinant is the chemotherapy regimen's emetogenicity. ${ }^{16}$ Antiemetic guidelines classify chemotherapeutic agents as having high, moderate, low, or minimal risk of inducing CINV. ${ }^{16-19}$ Without effective prophylaxis, highly emetogenic chemotherapy (HEC) induces vomiting in $>90 \%$ of patients who receive it, and moderately emetogenic chemotherapy (MEC) induces vomiting in 30\%-90\% of recipients. ${ }^{16} \mathrm{CINV}$ has a relapsing-remitting-relapsing time course. Patients usually experience intense CINV within 1-2 hours of initiating chemotherapy, lasting for about 24 hours (acute phase). Symptoms usually recede, but reemerge at 48-72 hours (delayed phase). ${ }^{20}$

Guidelines for CINV prophylaxis have been developed by the National Comprehensive Cancer Network (NCCN), ${ }^{16}$ American Society of Clinical Oncology (ASCO), ${ }^{17}$ and Multinational Association of Supportive Care in Cancer (MASCC) and European Society of Medical Oncology. ${ }^{18,19}$ These include recommendations for preventing acute and delayed CINV tailored to the emetogenicity of the chemotherapy regimen. ${ }^{16-19}$ For most patients receiving HEC or MEC, a three- or four-drug regimen is recommended to prevent acute CINV. ${ }^{16-19}$ The standard three-drug regimen consists of a combination of a 5-hydroxytryptamine type 3 $\left(5 \mathrm{HT}_{3}\right)$-receptor antagonist (RA), a neurokinin $1\left(\mathrm{NK}_{1}\right) \mathrm{RA}$, and dexamethasone, ${ }^{16-19}$ with olanzapine added for four-drug regimens recommended by ASCO and NCCN for patients receiving HEC. ${ }^{16,17}$ The MASCC guidelines recommend a three-drug regimen of a $5 \mathrm{HT}_{3} \mathrm{RA}$ and dexamethasone with either an $\mathrm{NK}_{1} \mathrm{RA}$ or olanzapine (if nausea is an issue)..$^{18}$ NCCN guidelines offer an alternative three-drug regimen for HEC or MEC: olanzapine, palonosetron, and dexamethasone. ${ }^{16}$ Patients receiving HEC or MEC should also receive antiemetics on chemotherapy days 2-4 to prevent delayed CINV, the choice of agent(s) depending on the antiemetic regimen received for acute CINV prophylaxis. ${ }^{16-19}$

Antiemetic prophylaxis aims for complete CINV prevention, ${ }^{20}$ best achieved with multiple agents targeting different emetogenic pathways. ${ }^{16}$ Unfortunately, many patients do not receive guideline-recommended antiemetic regimens, ${ }^{21-25}$ so are more likely to experience CINV. ${ }^{21,23-25}$ The reasons for poor adherence to CINV-guideline recommendations are unclear, but evidence suggests that physicians and patients perceive CINV differently. ${ }^{26,27}$ For example, physicians tend to underestimate the nausea that patients experience, ${ }^{25}$ particularly during the delayed phase, ${ }^{26}$ and prescribers, but not patients, often identify cost as a barrier to using effective antiemetic prophylaxis. ${ }^{27}$

Despite comprehensive antiemetic guidelines, unmet medical needs remain in CINV management, especially for better nausea control (particularly delayed nausea). Moreover, use of certain drug classes, especially $\mathrm{NK}_{1}$ RAs, is suboptimal, ${ }^{23,24}$ possibly reflecting a poor understanding of their appropriate use. This review aims to examine the pharmacologic, pharmacokinetic, and clinical features of $\mathrm{NK}_{1} \mathrm{RAs}$ and how they affect clinical efficacy and safety, enabling physicians to make informed, evidence-based, and rational therapeutic decisions about using these agents for CINV prophylaxis.

\section{Overview of NK, RAs}

CINV is mediated by a complex neural network in the gut and central nervous system, so combination antiemetic regimens are indicated to target multiple pathways. One pathway involves the action of substance $\mathrm{P}$ on $\mathrm{NK}_{1}$ receptors in the gut and central nervous system. Chemotherapy induces substance $P$ release in these regions during acute and delayed CINV, so blocking the $\mathrm{NK}_{1}$ receptor may prevent acute and delayed emesis. ${ }^{28} \mathrm{In}$ addition, there is evidence of "cross talk" between the emetic pathways, such that a combination of a $5 \mathrm{HT}_{3} \mathrm{RA}$ and an $\mathrm{NK}_{1} \mathrm{RA}$ has synergistic antiemetic effects. ${ }^{28}$

Several $\mathrm{NK}_{1}$ RAs are available in the United States for use in combination with other antiemetics for CINV prevention. Aprepitant (Emend; Merck, Whitehouse Station, NJ), rolapitant (Varubi; Tesaro, Waltham, MA), and netupitant (Akynzeo; Helsinn Therapeutics, Iselin, NJ) are orally administered. ${ }^{29-31}$ Fosaprepitant (Emend IV; Merck) is a prodrug of aprepitant, permitting intravenous (IV) administration. ${ }^{32}$ In late 2017, IV formulations of aprepitant (HTX019, Cinvanti; Heron Therapeutics, San Diego, CA) free of polysorbate 80 and other synthetic surfactants ${ }^{33}$ and rolapitant ${ }^{31}$ were approved in the United States. Most recently, in April 2018, fosnetupitant (Akynzeo), the prodrug of netupitant, was approved in the United States, allowing IV administration of netupitant. ${ }^{29}$ Unlike the other $\mathrm{NK}_{1}$ RAs, netupitant and fosnetupitant are available only in a fixed 
combination with the $5 \mathrm{HT}_{3} \mathrm{RA}$ palonosetron (netupitant/ palonosetron [NEPA] oral or IV). ${ }^{29}$

\section{Approved NK, RAs Formulations and indications}

Orally administered $\mathrm{NK}_{1}$ RAs are available as tablets, capsules, and oral suspension. ${ }^{29-31}$ The aprepitant oral suspension can be used in almost any age-group, including in infants aged $\geq 6$ months, while aprepitant capsules are only for patients aged $\geq 12$ years. ${ }^{30}$

Currently approved $\mathrm{NK}_{1}$ RAs have similar but subtly different indications listed in their prescribing information. The approved formulations are summarized in Table 1 according to their brand name, route of administration, indication, and year of approval. ${ }^{29-33} \mathrm{IV}$ aprepitant (Cinvanti) is a polysorbate 80- and synthetic surfactant-free formulation containing natural excipients. ${ }^{33}$ Fosnetupitant (the prodrug of netupitant included in IV NEPA) was developed without the need for a surfactant emulsifier or solubility enhancer. ${ }^{29,34}$ The IV formulation of fosaprepitant contains polysorbate $80,{ }^{32}$ and IV rolapitant (Varubi) contains the synthetic surfactant polyoxyl 15 hydroxystearate. ${ }^{31}$

\section{Pharmacokinetic, receptor occupancy, and pharmacodynamic properties}

Table 2 summarizes the pharmacokinetic characteristics of the $\mathrm{NK}_{1}$ RAs currently approved in the United States and the agents' occupancy of $\mathrm{NK}_{1}$ receptors in the brain. According to current US prescribing information, in healthy volunteers all of the oral formulations reach maximum plasma levels $\left(\mathrm{C}_{\max }\right)$ in 3-5 hours. ${ }^{29-31,35}$ For IV formulations, $\mathrm{C}_{\max }$ is reached within 30 minutes of the start of infusion. ${ }^{31-33}$ The elimination half-life $\left(t_{1 / 2}\right)$ in healthy volunteers is 9-13 hours for aprepitant after oral or IV administration, ${ }^{30,32,33}$ but considerably longer for netupitant (oral 96 hours, IV 144 hours) and rolapitant (IV or oral 169-183 hours). ${ }^{29,31}$ The long $t_{1 / 2}$ of rolapitant explains why a single dose administered 1-2 hours before

Table I Formulations of approved NK, RAs

\begin{tabular}{|c|c|c|c|}
\hline Drug (brand name) & Administration route & Indication & Year of approval \\
\hline Aprepitant (Emend) ${ }^{30}$ & $\begin{array}{l}\text { PO (capsules or } \\
\text { suspension) }\end{array}$ & $\begin{array}{l}\text { In adults (capsules or suspension) and pediatric patients (suspension, } \\
\text { aged } \geq 6 \text { months; capsules, aged } \geq 12 \text { years), in combination with other } \\
\text { antiemetics for: } \\
\text { acute and delayed NV associated with initial and repeat courses of HEC, } \\
\text { including high-dose cisplatin } \\
N V \text { associated with initial and repeat courses of MEC (adults and } \\
\text { pediatrics) } \\
\text { in adults (capsules) for PONV }\end{array}$ & 2003 \\
\hline Fosaprepitant (Emend) ${ }^{32}$ & IV & $\begin{array}{l}\text { In adults and pediatric patients aged } \geq 6 \text { months, in combination with } \\
\text { other antiemetics for: } \\
\text { acute and delayed NV associated with initial and repeat courses of HEC, } \\
\text { including high-dose cisplatin } \\
\text { delayed } N V \text { associated with initial and repeat courses of MEC }\end{array}$ & 2008 \\
\hline $\begin{array}{l}\text { Netupitant/palonosetron } \\
\text { capsule (Akynzeo) })^{29}\end{array}$ & $\mathrm{PO}$ & $\begin{array}{l}\text { In adults in combination with dexamethasone for: } \\
\text { acute and delayed NV associated with initial and repeat courses of } \\
\text { chemotherapy, including but not limited to HEC }\end{array}$ & $\begin{array}{l}\text { US: } 2014 \\
\text { EU: } 2015\end{array}$ \\
\hline $\begin{array}{l}\text { Rolapitant tablet } \\
\text { (Varubi) }^{31}\end{array}$ & PO & $\begin{array}{l}\text { In adults in combination with other antiemetic agents for: } \\
\text { delayed NV associated with initial and repeat courses of emetogenic } \\
\text { chemotherapy, including but not limited to HEC }\end{array}$ & US: 2015 \\
\hline Rolapitant IV ${ }^{a}\left(V^{2}\right.$ rubi) ${ }^{31}$ & IV & $\begin{array}{l}\text { In adults in combination with other antiemetic agents for: } \\
\text { delayed NV associated with initial and repeat courses of emetogenic } \\
\text { chemotherapy, including but not limited to HEC }\end{array}$ & US: 2017 \\
\hline $\begin{array}{l}\text { Aprepitant IV } \\
\left(_{(\text {Cinvanti })^{33}}\right.\end{array}$ & IV & $\begin{array}{l}\text { In adults in combination with other antiemetics: } \\
\text { acute and delayed NV associated with initial and repeat courses of HEC, } \\
\text { including high-dose cisplatin } \\
\text { NV associated with initial and repeat courses of MEC }\end{array}$ & US: 2017 \\
\hline $\begin{array}{l}\text { Netupitant/palonosetron } \\
(\text { Akynzeo) })^{29}\end{array}$ & IV & $\begin{array}{l}\text { In adults in combination with dexamethasone: } \\
\text { acute and delayed NV associated with initial and repeat courses of HEC }\end{array}$ & US: 2018 \\
\hline
\end{tabular}

Note: a Manufacturer issued a press release on February 28, 2018 announcing the suspension of rolapitant IV distribution. ${ }^{89}$

Abbreviations: HEC, highly emetogenic chemotherapy; IV, intravenous; MEC, moderately emetogenic chemotherapy; NK, RAs, neurokinin I-receptor antagonists; PO, per os (oral). 


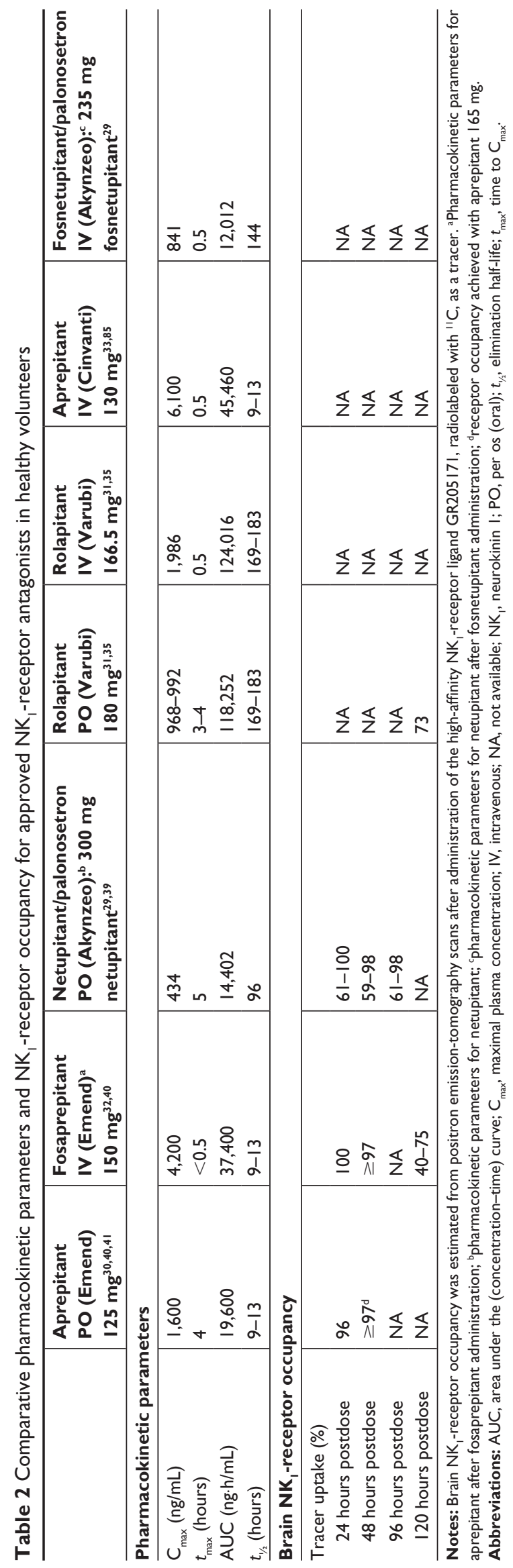

chemotherapy is expected to prevent delayed CINV, as its protection against CINV is established for up to 5 days. ${ }^{36-38}$ However, rolapitant takes longer to achieve therapeutic concentrations, so may be less effective in the acute phase. ${ }^{31}$ In patients with cancer, systemic exposure to netupitant is lower than in healthy volunteers, but this has been reported to be clinically insignificant. ${ }^{29}$

Plasma pharmacokinetic profiles of different $\mathrm{NK}_{1}$ RAs suggest that all can rapidly bind to $\mathrm{NK}_{1}$ receptors; however, there may be differences in the inherent ability of different $\mathrm{NK}_{1}$ RAs to cross the blood-brain barrier. ${ }^{35,39-41}$ Receptor occupancy (RO) studies conducted in healthy volunteers have suggested that aprepitant reaches full RO within 24 hours. ${ }^{41}$ $\mathrm{NK}_{1}$ RO by netupitant has been reported 24-96 hours postdose, and varies in different brain regions ${ }^{39} \mathrm{Brain}_{\mathrm{NK}} \mathrm{RO}$ at 120 hours postdose has been reported at levels of $40 \%-75 \%$ for IV fosaprepitant $\mathrm{t}^{40}$ and $94 \%$ for oral rolapitant. ${ }^{41}$ Oral and IV rolapitant are highly plasma-bound (99.8\%), ${ }^{31}$ which in conjunction with its longer $t_{1 / 2}$ provides support for the high RO seen at 120 hours postdose, but RO data on earlier time points were not provided for either of the rolapitant formulations. ${ }^{31}$

Pharmacodynamics indicate that all $\mathrm{NK}_{1}$ RAs undergo hepatic metabolism, with the potential to cause drug-drug interactions via the CYP enzyme system. ${ }^{29-33}$ Aprepitant and its prodrug fosaprepitant are substrates for CYP3A4. They can induce the enzyme and inhibit it weakly to moderately. Aprepitant and fosaprepitant also induce CYP2C9. As a result, concurrent use of the antipsychotic agent pimozide, a CYP3A4 substrate, is contraindicated with aprepitant or fosaprepitant, and there are warnings about using aprepitant (oral or IV) or fosaprepitant with other agents that are CYP3A4 substrates. ${ }^{30,32}$ Furthermore, using these agents with strong or moderate CYP3A4 inhibitors (eg, ketoconazole or diltiazem) may increase plasma concentrations of aprepitant, leading to an increased risk of drug-related adverse events. Conversely, the use of aprepitant or fosaprepitant formulations with strong CYP3A4 inducers (eg, rifampin) may reduce aprepitant plasma concentrations and decrease its efficacy. ${ }^{30,32,33}$ Because aprepitant and fosaprepitant induce CYP2C9, they can affect the clotting response to warfarin, so patients taking concomitant warfarin should have their international normalized ratio monitored..$^{30,32,33}$ Aprepitant and fosaprepitant can also reduce the efficacy of oral contraceptives.

Rolapitant is also slowly metabolized by CYP3A4, but does not induce or inhibit this enzyme. ${ }^{42}$ However, rolapitant metabolism also involves CYP2D6, so rolapitant should be used with caution in combination with other substrates for 
this enzyme if they have a narrow therapeutic index. ${ }^{31}$ For this reason, thioridazine is contraindicated in patients receiving rolapitant, and pimozide should be avoided..$^{31}$ Rolapitant also inhibits the efflux transporters P-glycoprotein and BCRP, so increases systemic exposure to agents that are substrates of these transporters, including digoxin and sulfasalazine. ${ }^{42}$

NEPA has no specific contraindications, but prescribing information includes warnings about the potential for hypersensitivity reactions and serotonin syndrome. As listed in the prescribing information, limitations of use include the fact that IV NEPA has not been studied in patients receiving anthracycline plus cyclophosphamide (AC)-based HEC and thus lacks data on potential hypersensitivity reactions in this group of patients. Because netupitant inhibits CYP3A4, drugs that are substrates or inducers of this enzyme should be avoided when NEPA is prescribed. ${ }^{29}$

\section{Clinical efficacy: complete response}

A PubMed literature search was undertaken for clinical studies in patients at risk of CINV from 2003 to 2018, in which any approved $\mathrm{NK}_{1}$ RA appeared in the title or abstract of the publication. A similar search was performed for published abstracts presented at major supportive-care congresses, ie, MASCC, ASCO, ASCO Palliative and Supportive Care Conference, and European Society of Medical Oncology, from 2016 to 2018 . The results identified studies in which a threedrug regimen of an $\mathrm{NK}_{1} \mathrm{RA}$, a $5 \mathrm{HT}_{3} \mathrm{RA}$, and dexamethasone was compared with a two-drug combination of a $5 \mathrm{HT}_{3} \mathrm{RA}$ and dexamethasone.

\section{Efficacy with highly emetogenic chemotherapy}

Randomized controlled trials in patients receiving HEC are summarized in Table $3 .^{36-38,43-56}$ The primary end point in most studies was complete response (CR), ie, no episodes of vomiting and no rescue antiemetic therapy. Most studies showed a significantly greater CR rate over the 5-day assessment period in groups receiving triple therapy compared with dual therapy. ${ }^{36-38,43,46-48,51,53-55}$ The exceptions were a study of fosaprepitant in women with gynecologic cancers undergoing combined radiotherapy and chemotherapy ${ }^{52}$ and two Japanese studies of oral aprepitant in patients with non-small-cell lung cancer who were receiving carboplatin-based regimens. ${ }^{49,50}$ In the Japanese studies, oral aprepitant-based triple therapy was significantly more effective than dual therapy in the subgroup of patients receiving carboplatin and pemetrexed \pm bevacizumab, but not in those receiving carboplatin and paclitaxel \pm bevacizumab. ${ }^{49,50}$ The current NCCN guidelines classify carboplatin as HEC (where a three- or four-drug antiemetic regimen is recommended) if given at high doses, area under the concentration-time curve $(\mathrm{AUC}) \geq 4$, and as $\mathrm{MEC}$ if $\mathrm{AUC}<4 .^{16}$

Another consistent finding in comparative studies was a significantly higher rate of delayed CINV control with $\mathrm{NK}_{1}$ RA-containing triple therapy vs steroid plus $5 \mathrm{HT}_{3}$ - $\mathrm{RA}$ dual therapy. ${ }^{36-38,43,46-48,51,53-55}$ Most studies also showed a higher CR rate during the acute phase. ${ }^{36,37,43,46-48,51,53-55}$ In addition, meta-analyses of randomized clinical trials have confirmed the significant and clinically relevant improvement in CR in patients receiving carboplatin-based chemotherapy when treated with the three-drug regimen containing an $\mathrm{NK}_{1} \mathrm{RA}$ compared with the dual-therapy combination. ${ }^{57}$

Because female sex is a known risk factor for increased CINV, ${ }^{58}$ some $\mathrm{NK}_{1}-\mathrm{RA}$ studies have analyzed $\mathrm{CR}$ rates in male and female participants receiving HEC. In a subgroup analysis of a trial in which patients received a $5 \mathrm{HT}_{3} \mathrm{RA}$ plus dexamethasone with or without oral aprepitant, CR rates in the oral aprepitant group were slightly lower in female $(68.6 \%)$ than male $(71.2 \%)$ participants, but still higher than with the two-drug regimen $(36.8 \%$ and $55.0 \%$, respectively). ${ }^{55}$ Similarly, in a post hoc multivariate analysis of two trials in which patients received a $5 \mathrm{HT}_{3} \mathrm{RA}$ plus dexamethasone with or without oral aprepitant, male sex was significantly associated with improved CR $(P=0.023)$, but oral aprepitant improved $\mathrm{CR}$ regardless of patient sex. ${ }^{59}$ In a trial of oral palonosetron plus dexamethasone with or without oral netupitant, CR rates were higher in male than female participants, but all patients receiving oral NEPA had an incremental benefit in terms of CR. ${ }^{47}$ Therefore, although some differences in $\mathrm{CR}$ rates have been observed between male and female participants, both groups benefit from the addition of an $\mathrm{NK}_{1}$ RA to a two-drug antiemetic regimen.

Across all randomized controlled trials, the magnitude of treatment difference in overall $\mathrm{CR}$ rate between two-drug and three-drug regimens for all patients ranged 3.6\%-33\% for oral aprepitant, ${ }^{43-46,48-51,54,55} 7 \%-17 \%$ for fosaprepitant, ${ }^{52,53}$ $13.1 \%$ for oral netupitant, ${ }^{47}$ and $7.9 \%-15.8 \%$ for oral rolapitant. ${ }^{36-38}$ Aside from one study, the treatment difference in CR was consistently higher during the delayed vs acute phase. ${ }^{36}$

It is difficult to compare treatment differences across studies, because of the variable patient populations and treatment regimens (ie, most HEC studies were cisplatin-based; Table 3). In some studies, patients in the three-drug arm received lower doses of dexamethasone than patients in the two-drug arm, ${ }^{44-47,51,53-55}$ whereas in other studies the dexamethasone dose was the same in both arms. ${ }^{36-38,43,49,50,52}$ 


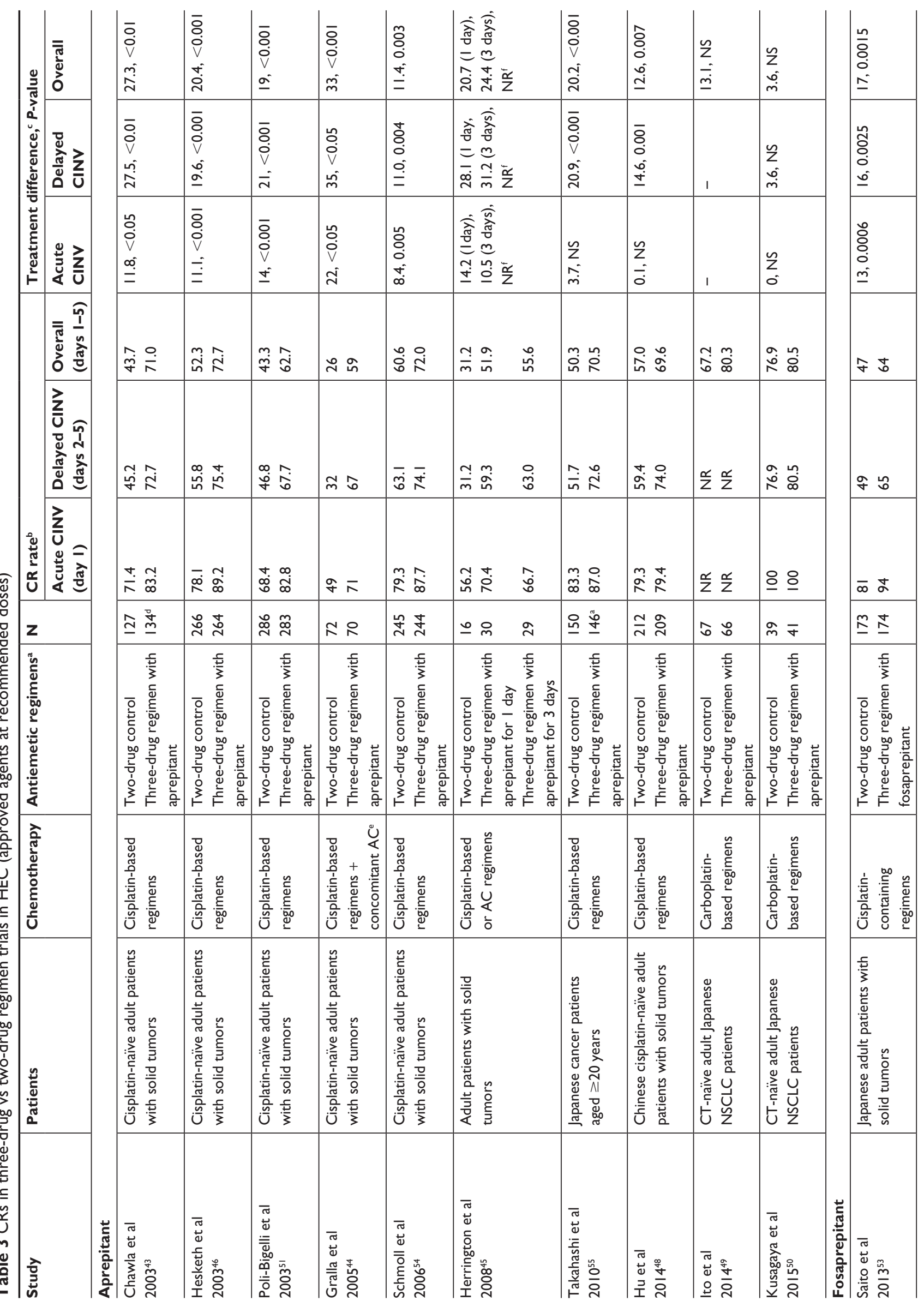




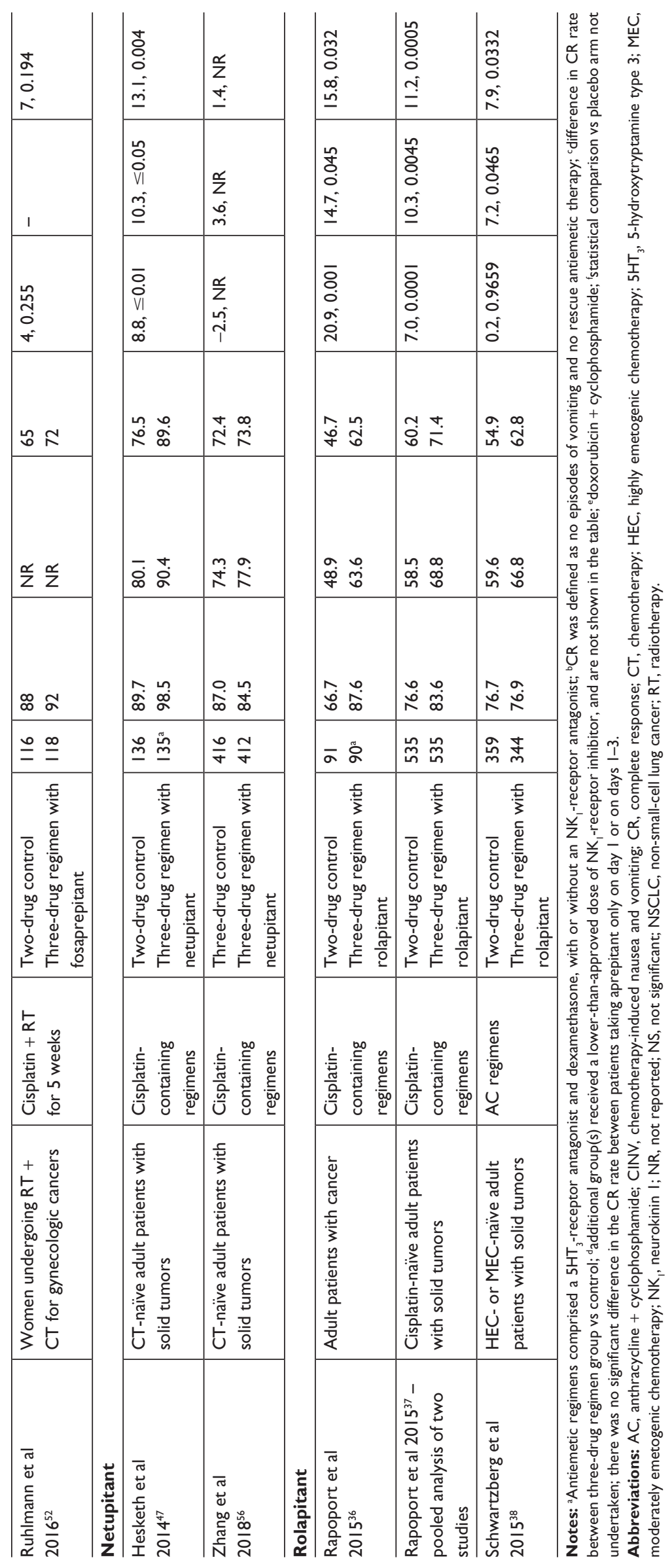


Several meta-analyses have confirmed that three-drug regimens containing an $\mathrm{NK}_{1} \mathrm{RA}$ are significantly more effective than two-drug regimens for achieving $\mathrm{CR}$ in patients with CINV. ${ }^{60-62}$ The estimated risk difference for overall CR between the two types of antiemetic regimens is $14 \%(95 \%$ CI $12 \%-17 \%$ ) in patients receiving any type of HEC, $16 \%$ (95\% CI 14\%-19\%) in patients receiving cisplatin-based HEC, and $11 \%(95 \% \mathrm{CI} 7 \%-15 \%)$ in patients receiving AC-based HEC, ${ }^{61}$ all of which exceed the level considered to be clinically meaningful $(\geq 10 \%){ }^{63,64}$

Few studies have directly compared the efficacy of three-drug antiemetic regimens using different $\mathrm{NK}_{1}$ RAs. Studies directly comparing different three-drug regimens in patients receiving HEC have found similar CR rates among regimens. For example, comparable rates of overall, acute, and delayed $\mathrm{CR}$ were reported in patients receiving a fosaprepitant- or oral aprepitant-based three-drug regimen. ${ }^{65} \mathrm{In}$ a comparison of $\mathrm{CR}$ rates in patients receiving oral NEPA plus dexamethasone vs those receiving oral aprepitant plus ondansetron plus dexamethasone as an exploratory end point, there was no statistical significance, ${ }^{47}$ and the threshold of clinically meaningful difference was not met, ${ }^{63,64}$ as shown in Table 3. In a recent study, CR rates showed noninferiority of oral NEPA plus dexamethasone vs oral aprepitant plus granisetron plus dexamethasone. ${ }^{56}$ Another study showed no significant difference between oral NEPA-based and oral aprepitant-based triple therapy in patients receiving HEC, ${ }^{66}$ including in the subgroup of patients receiving carboplatinbased chemotherapy. ${ }^{67}$

Recently, researchers have investigated the effect of adding olanzapine to a three-drug antiemetic combination in randomized, double-blind, placebo-controlled trials with aprepitant or fosaprepitant. ${ }^{68,69}$ The olanzapine plus threedrug combination elicited a significantly higher CR rate in the acute, delayed, and overall phases compared with placebo plus a three-drug combination in patients receiving HEC. ${ }^{69}$ A study in patients receiving HEC or MEC also found significantly higher $\mathrm{CR}$ rates with olanzapine treatment in the delayed and overall phases. ${ }^{68}$

\section{Efficacy with moderately emetogenic chemotherapy}

Studies in which an $\mathrm{NK}_{1}$ RA was added to a standard twodrug regimen of a $5 \mathrm{HT}_{3} \mathrm{RA}$ and dexamethasone in patients receiving MEC are summarized in Table 4. ${ }^{38,70-82}$ However, in some studies, patients received chemotherapy regimens that have since been recategorized as HEC,,$^{70,71,80-82}$ such as AC-based regimens. Carboplatin is now classified as HEC if given at high doses (AUC $\geq 4$ ) and as MEC at lower doses (AUC <4). ${ }^{16}$ Most studies have shown a significantly greater improvement in overall CR rates with the three-drug vs the two-drug regimen, with greater differences observed in HEC-treated patients..$^{70-72,75-80}$ Like the HEC studies, the triple-antiemetic combination tended to have a more marked effect on CR rates in the delayed than the acute phase in patients receiving MEC. This difference between acute and delayed antiemetic effect was most marked in two studies in which patients were receiving carboplatin-based chemotherapy for solid tumors ${ }^{47,80}$ and another in which patients with multiple myeloma were receiving high-dose melphalan prior to autologous stem-cell transplant. ${ }^{77}$

Female sex is one of several risk factors for increased CINV, ${ }^{58}$ and a difference in CR rates in the overall phase between male $(83.0 \%)$ and female $(77.9 \%)$ patients was reported in a trial of a $5 \mathrm{HT}_{3}$ RA plus dexamethasone with or without oral rolapitant in patients receiving carboplatinbased chemotherapy. However, both groups had significantly higher $\mathrm{CR}$ rates than the sex-matched patients in the control group $\left(67.7 \%\right.$ and $62.1 \%$, respectively). ${ }^{72}$

A recent meta-analysis supported the incremental benefit of an $\mathrm{NK}_{1} \mathrm{RA}$, and suggested that the magnitude of effect of $\mathrm{NK}_{1} \mathrm{RA}$-based triple therapy on $\mathrm{CR}$ varied depending on the MEC regimen administered. ${ }^{83}$ The effect on overall CR was greatest in patients who were receiving carboplatin-based chemotherapy (Figure 1), with a risk difference of $15 \%$ between two-drug regimens and $\mathrm{NK}_{1}$ RA-based three-drug regimens. A significant effect in favor of the three-drug regimen was also seen in patients who received MEC that did not contain oxaliplatin or carboplatin, but not in patients receiving oxaliplatin-based regimens. ${ }^{83}$ The odds of achieving CR in the acute and delayed phases were significantly better with the three-drug than with the two-drug regimens in patients taking carboplatin. Also, delayed CR rates were significantly higher following a three-drug regimen in MEC patients not receiving oxaliplatin or carboplatin (Figure 1). ${ }^{83}$

For patients receiving MEC, current guidelines recommend $\mathrm{NK}_{1}$ RAs in those at high risk of CINV. ${ }^{16}$ These include female patients, those aged $<55$ years, people without a history of habitual alcohol use, and nonsmokers. ${ }^{84}$

\section{Clinical efficacy: nausea control}

Because CR and other measures of antiemetic efficacy generally focus on control of emesis, some trials have also included nausea end points, although nausea control is typically a secondary or exploratory end point. This patient-reported outcome is often measured using a $100 \mathrm{~mm}$ VAS ( 0 , no nausea; 100 , worst possible nausea $)^{36,46,56}$ or a 4-point nausea-severity score ( 0 , none; 1 , mild; 2 , moderate; 3, severe). ${ }^{53,55,75}$ End points reported include "no nausea" 


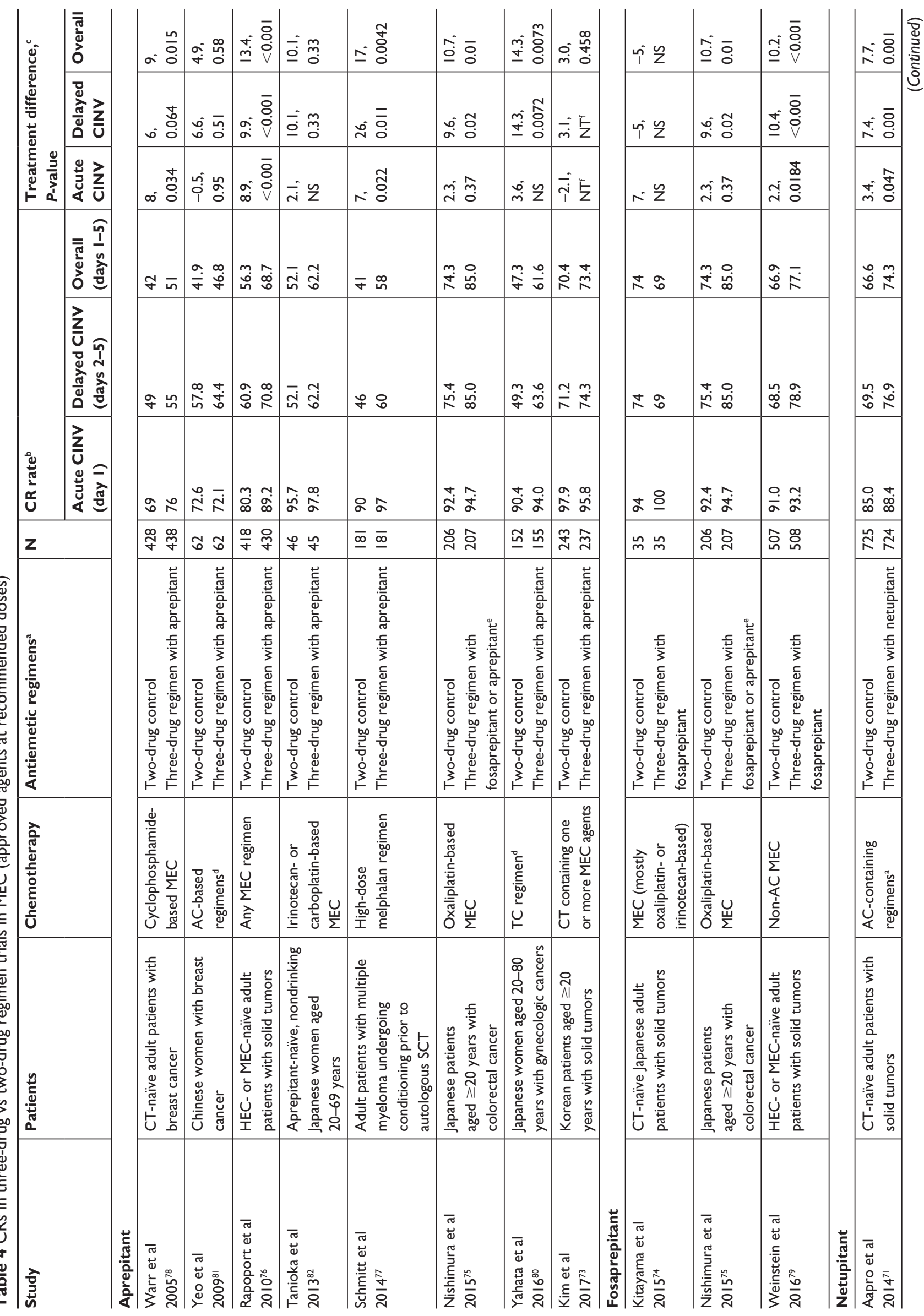




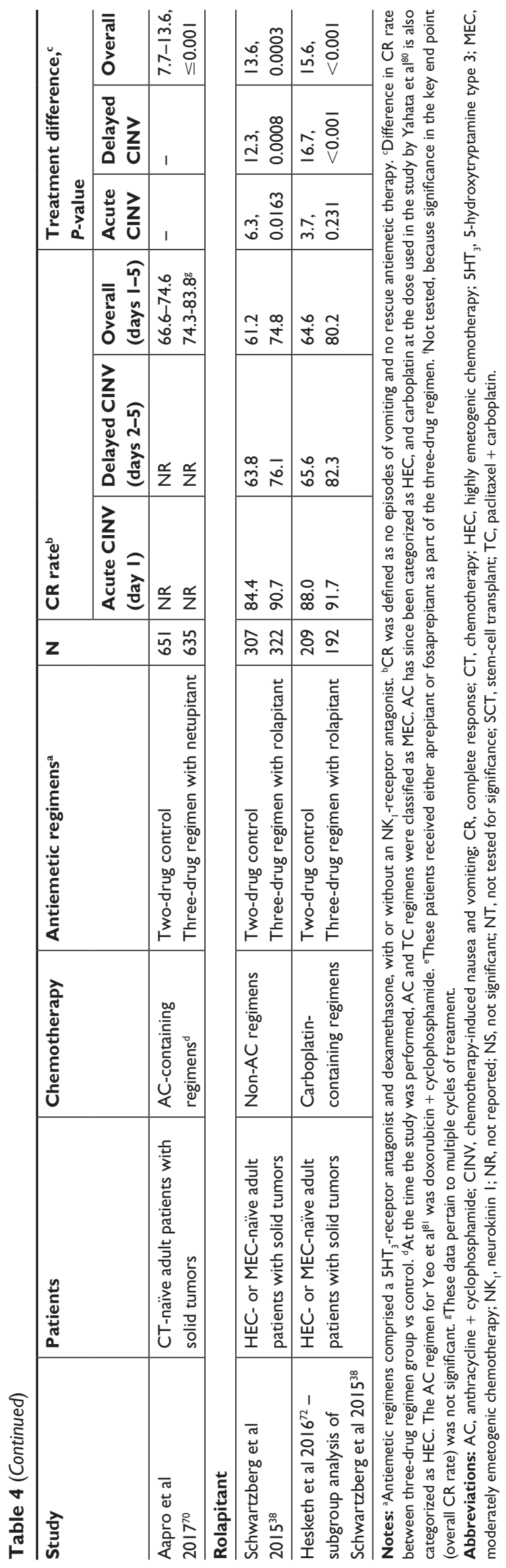

$(<5 \mathrm{~mm} \text { on } 100 \mathrm{~mm} \text { VAS or } 0 \text { on a 4-point scale })^{36,46,56}$ and "no significant nausea" $(<25 \mathrm{~mm}$ on $100 \mathrm{~mm}$ VAS or 0 and 1 on a 4-point scale), $, 53,55,75$ and assessments may be made during acute, delayed, and overall phases, but are more often assessed during the overall phase.

\section{Efficacy with highly emetogenic chemotherapy}

Randomized controlled trials in patients receiving HEC are summarized in Table 5. ${ }^{36,37,43,46,47,49,51-56}$ Most of these trials reported no significant improvements in nausea control (percentage of patients with no nausea or no significant nausea) in any CINV phase with the addition of an $\mathrm{NK}_{1}$ RA to a two-drug antiemetic regimen. Of those trials that did report a significant improvement in nausea control during any phase, ${ }^{36,37,43,47,51,55}$ only two trials and one pooled analysis of two trials reported significant improvements in nausea control across the acute, delayed, and overall phases. ${ }^{36,37,47}$ In trials where addition of an $\mathrm{NK}_{1}$ RA significantly improved nausea control in the overall phase (which was assessed most frequently), nausea-control rates ranged $49 \%-52.7 \%$ for "no nausea" $37,43,51$ and $52 \%-89.6 \%$ for "no significant nausea" ${ }^{n 7,47}$ in patients who received the three-drug regimen. However, comparisons across trials must be made with caution, because of differences in study design, patient populations, nausea assessments, chemotherapy regimens, and antiemetic regimens.

\section{Efficacy with moderately emetogenic chemotherapy}

Randomized controlled trials in patients receiving MEC are summarized in Table 6..$^{38,70-72,74-82}$ About half the MEC trials tabulated reported no significant improvements in nausea control in any CINV phase with the addition of an $\mathrm{NK}_{1}$ RA to a two-drug antiemetic regimen. Of those that did report a significant improvement in nausea control in any phase, ${ }^{70-72,75,76,79,80}$ none showed significant improvements in nausea control across the acute, delayed, and overall phases. In trials where addition of an $\mathrm{NK}_{1}$ RA significantly improved nausea control in the overall phase, nausea-control rates ranged $62.5 \%-74.6 \%$ for no nausea $^{71,72}$ and $73.6 \%-88.8 \%$ for no significant nausea ${ }^{75,76,79,80}$ in patients who received the three-drug regimen. However, again, differences in study design, patient populations, nausea assessments, chemotherapy, and antiemetic regimens administered limit comparisons across trials.

\section{Bioequivalence studies}

Approvals of IV rolapitant, HTX019 (IV formulation of aprepitant), and IV NEPA were based on demonstration of bioequivalence with the corresponding approved oral agents. ${ }^{31,33}$ A study in healthy volunteers showed that a single 


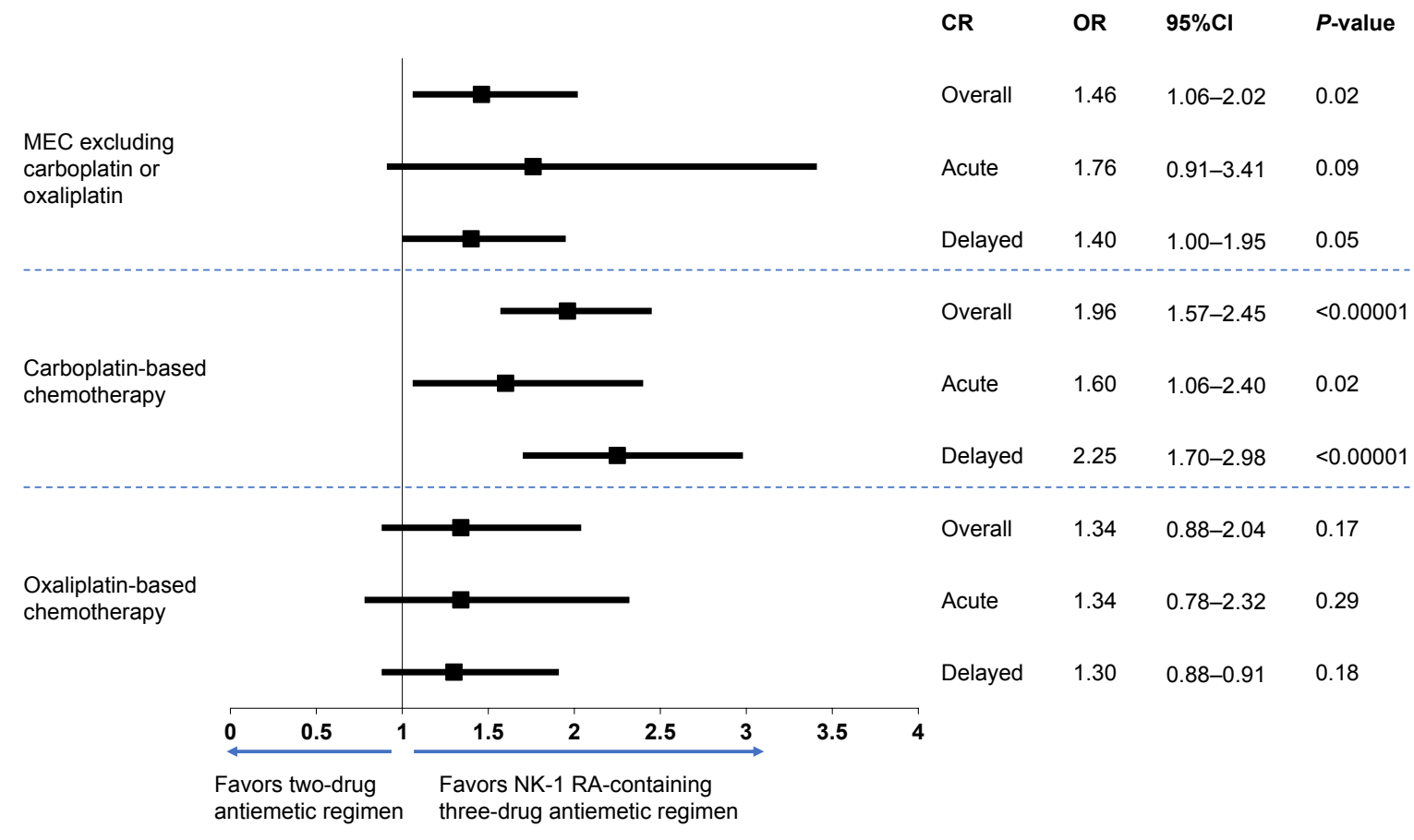

Figure I CR with $\mathrm{NK}_{1}$-RA-containing triple therapy vs dual therapy with a $5 \mathrm{HT}_{3}$ RA and dexamethasone.

Notes: ORs from a meta-analysis of randomized studies in patients receiving different types of MEC. Data from Jordan et al. ${ }^{83}$

Abbreviations: $\mathrm{CR}$, complete response; $5 \mathrm{HT}_{3}$, 5-hydroxytryptamine type 3; $\mathrm{MEC}$, moderately emetogenic chemotherapy; NK antagonist.

IV dose of rolapitant $166.5 \mathrm{mg}$ was bioequivalent to a single oral dose of $180 \mathrm{mg} .{ }^{35}$ As expected, $\mathrm{C}_{\text {max }}$ was higher with IV than with oral rolapitant, and occurred at an earlier time point, but the elimination $t_{1 / 2}$ was similar. Both rolapitant formulations were well tolerated, with a similar overall incidence of adverse events. ${ }^{35}$

A single dose of HTX019 $130 \mathrm{mg}$ was bioequivalent to the approved formulation of fosaprepitant $150 \mathrm{mg}$ IV in healthy volunteers. Plasma concentrations of aprepitant from both infusions were essentially superimposable at 0.75 hours after administration. Both agents were well tolerated, although HTX019 was associated with a lower rate of infusion reactions. ${ }^{85,86}$

\section{Safety}

In general, the $\mathrm{NK}_{1} \mathrm{RAs}$ are well tolerated and not associated with specific adverse events, ${ }^{87}$ although it can be difficult to distinguish adverse events related to antiemetics from those associated with chemotherapy. In randomized comparisons, the incidence of associated adverse events for three-drug regimens containing oral $\mathrm{NK}_{1}$ RAs was similar to that for two-drug regimens in patients receiving HEC or MEC. ${ }^{37,38,43,46,47,51,71,82}$ The most common adverse events with the oral agents are fatigue/asthenia, headache, hiccups, and constipation. ${ }^{87}$

In a bioequivalence study of healthy volunteers, oral and IV formulations of rolapitant had a similar overall incidence of adverse events. IV rolapitant contains polyoxyl 15 hydroxystearate, a synthetic surfactant with a limited safety profile. ${ }^{31,88,89}$ Two patients in the IV rolapitant group (2.8\%) developed a mild infusion-site reaction, and the incidence of headache was higher with IV than with oral rolapitant $(8.5 \%$ vs $3.0 \%$, respectively). ${ }^{35}$ In Phase I studies, IV rolapitant was less likely than oral rolapitant to exhibit drug interactions associated with P-glycoprotein or BCRP. ${ }^{42}$ Soon after the formulation's approval, a US Food and Drug Administration MedWatch safety alert was issued to health-care providers on January 16, 2018 warning against hypersensitivity reactions, including anaphylaxis and anaphylactic shock, which may occur during or following administration of IV rolapitant. Moreover, the alert recommended avoiding administration of the drug if the patient was hypersensitive to any ingredient of the drug formulation. ${ }^{88}$ Following that warning, a press release issued by the manufacturer on February 27, 2018 announced the suspension of IV rolapitant distribution. ${ }^{89}$

Fosaprepitant, the IV prodrug of aprepitant, is associated with a high incidence of infusion-site reactions and hypersensitivity, including anaphylaxis, ${ }^{32,90}$ and the prescribing information includes a warning about the risk of these events. ${ }^{32}$ Patients should be monitored during and after IV infusion of fosaprepitant, and discontinued if hypersensitivity reactions occur. ${ }^{32}$ In a Phase III trial of a two-drug regimen of a $5 \mathrm{HT}_{3}$ RA plus dexamethasone with or without fosaprepitant in patients scheduled to receive non-AC MEC, ${ }^{79}$ 


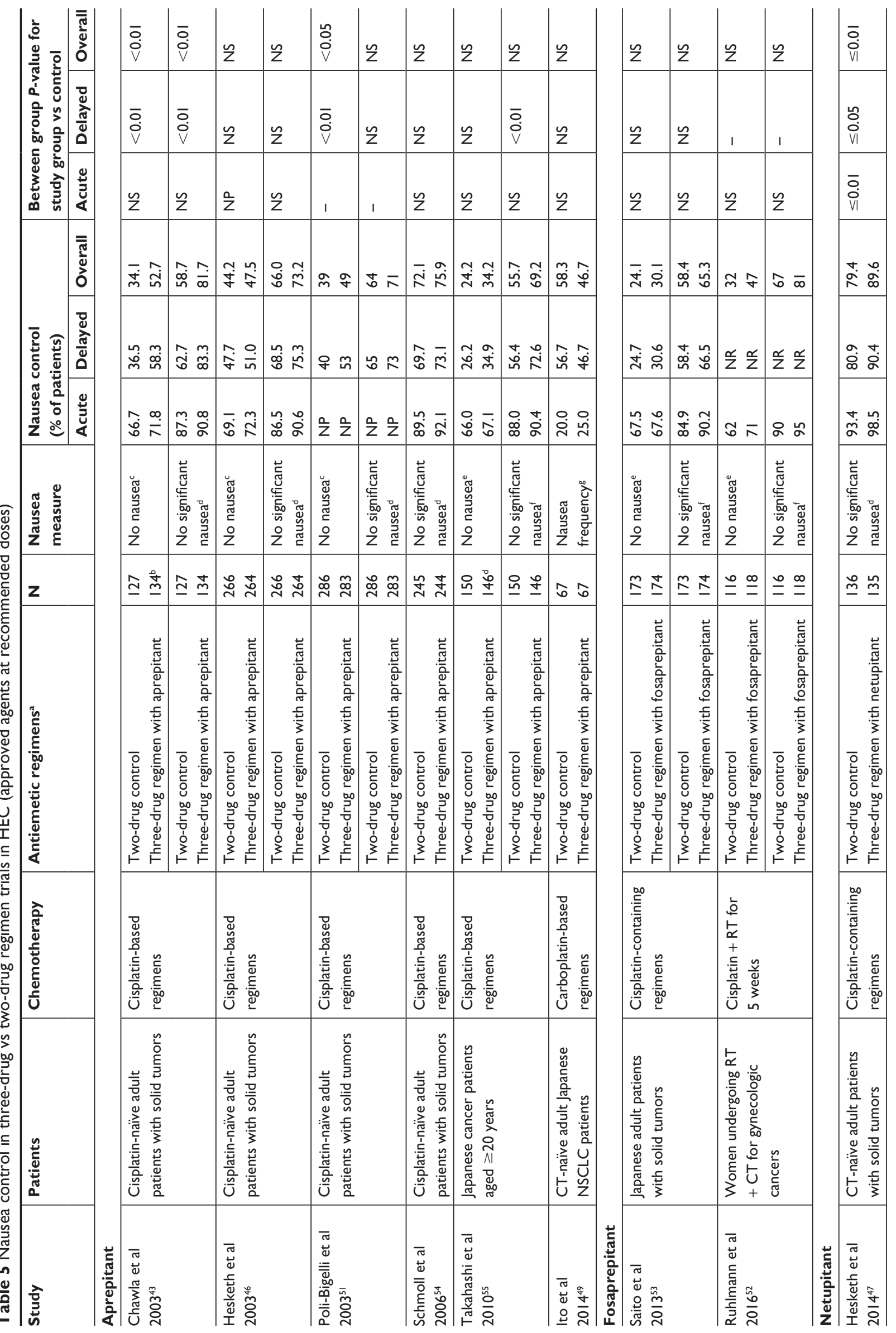




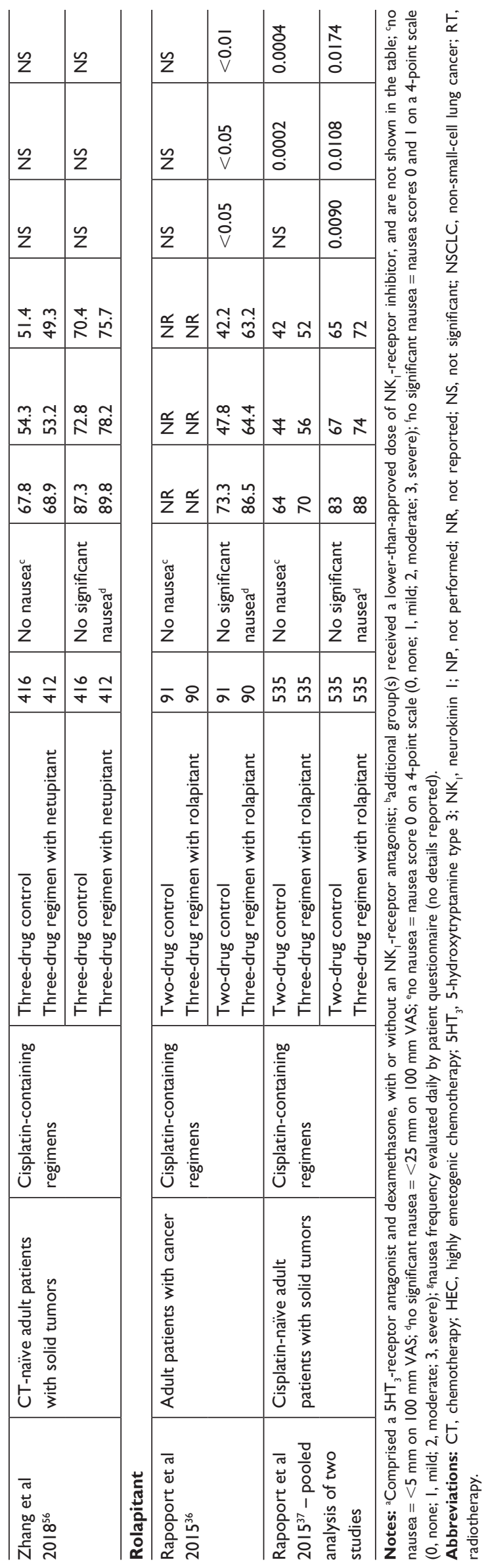

infusion-site reactions were reported in $2.2 \%$ of patients who received fosaprepitant compared with $0.6 \%$ of patients who did not. ${ }^{32}$ These reactions may be associated with polysorbate 80 , a surfactant used to solubilize fosaprepitant, and associated with infusion reactions and hypersensitivity when used in formulations of other pharmaceutical agents and vaccines. ${ }^{91,92}$ HTX019, the IV formulation of aprepitant, is free of polysorbate 80 and other synthetic surfactants. ${ }^{33} \mathrm{In}$ healthy volunteers, HTX019 was bioequivalent to fosaprepitant, but associated with a lower rate of infusion reactions. ${ }^{85}$ Within an hour of IV infusion, adverse events were reported in 20 participants receiving fosaprepitant and one participant receiving HTX019. ${ }^{85}$ However, as HTX019 contains aprepitant, the same active agent as fosaprepitant, the prescribing information for both IV agents includes the same warnings and precautions about hypersensitivity reactions..$^{32,33}$

Oral and IV formulations of NEPA are now approved in the United States. In a randomized, double-blind Phase III study comparing IV and oral NEPA (each with dexamethasone) prior to initial and repeated cycles of non-AC HEC in 404 patients, both NEPA formulations were similarly well tolerated. ${ }^{93,94}$ No serious adverse events related to IV or oral NEPA were recorded, the most common adverse event was constipation in both treatment groups, and the incidence of adverse events did not increase over repeated cycles. ${ }^{93,94}$ No patients receiving IV NEPA developed an infusion-site reaction. There were no clinically relevant electrocardiographic abnormalities or cardiac safety concerns with either formulation. . $33,94^{2}$

All $\mathrm{NK}_{1}$ RAs have the potential for drug-drug interactions, ${ }^{29-33}$ so careful assessment of concomitant medications is required when deciding which agent to use. For example, dexamethasone is a CYP3A4 substrate, so a lower dose of dexamethasone $(12 \mathrm{mg})$ is recommended on day 1 of antiemetic treatment with regimens containing oral or injectable emulsion aprepitant, fosaprepitant, or oral or IV NEPA than with regimens including oral rolapitant (dexamethasone $20 \mathrm{mg}) .{ }^{16}$ Because some $\mathrm{NK}_{1}$ RAs are substrates, weakmoderate (dose-dependent) inhibitors, and inducers of CYP3A4, they may increase the plasma concentrations of chemotherapeutic agents that are metabolized by CYP3A4, including taxanes, irinotecan, vinca alkaloids, and tyrosinekinase inhibitors..$^{87,95}$ Consequently, physicians should be vigilant for the possibility of an increased risk of adverse events when using NEPA, aprepitant, or fosaprepitant in patients receiving chemotherapy regimens containing these agents. Care should be taken when administering rolapitant with CYP2D6 substrates, including metoprolol and venlafaxine. ${ }^{87,92}$ 


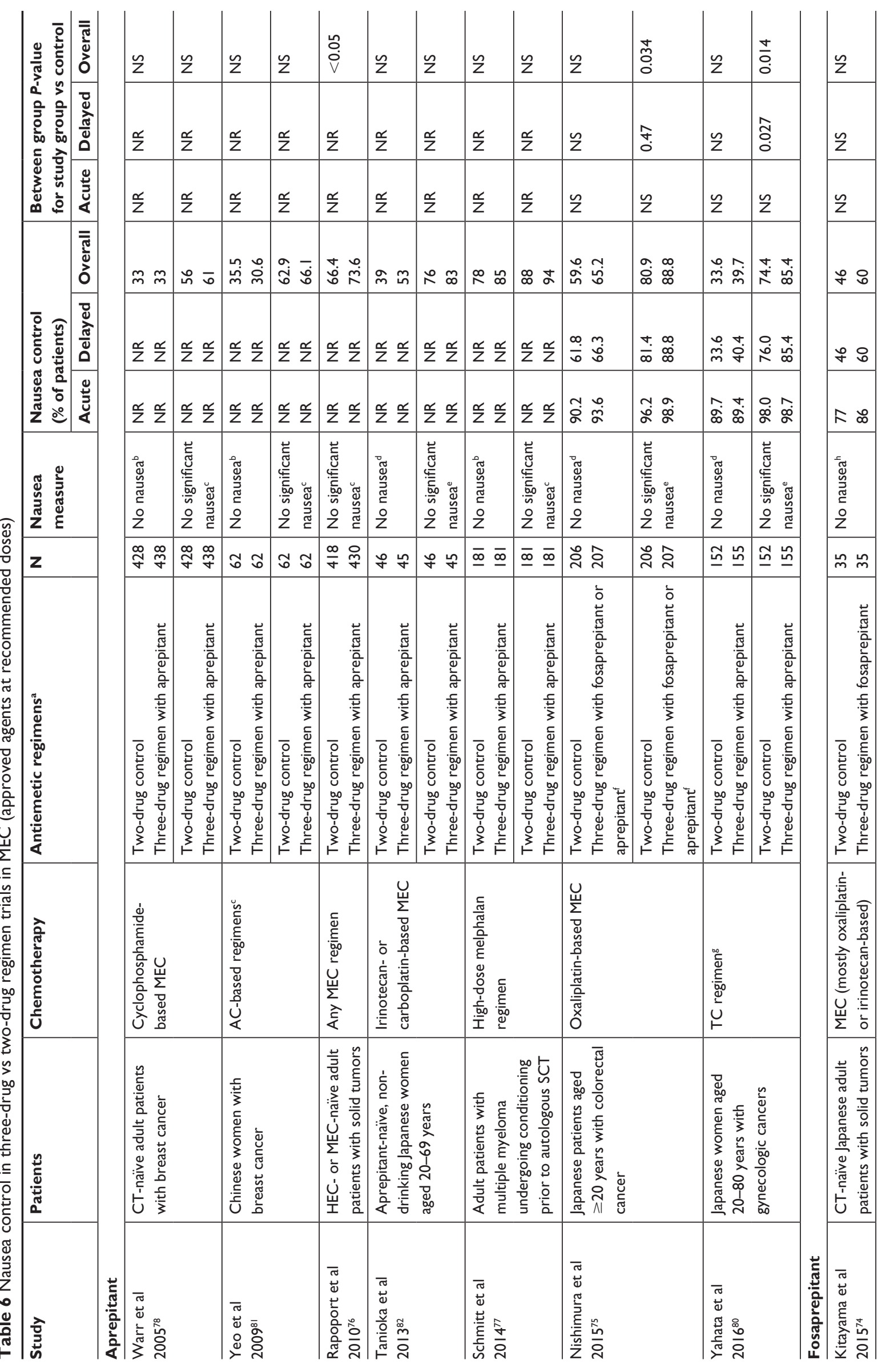




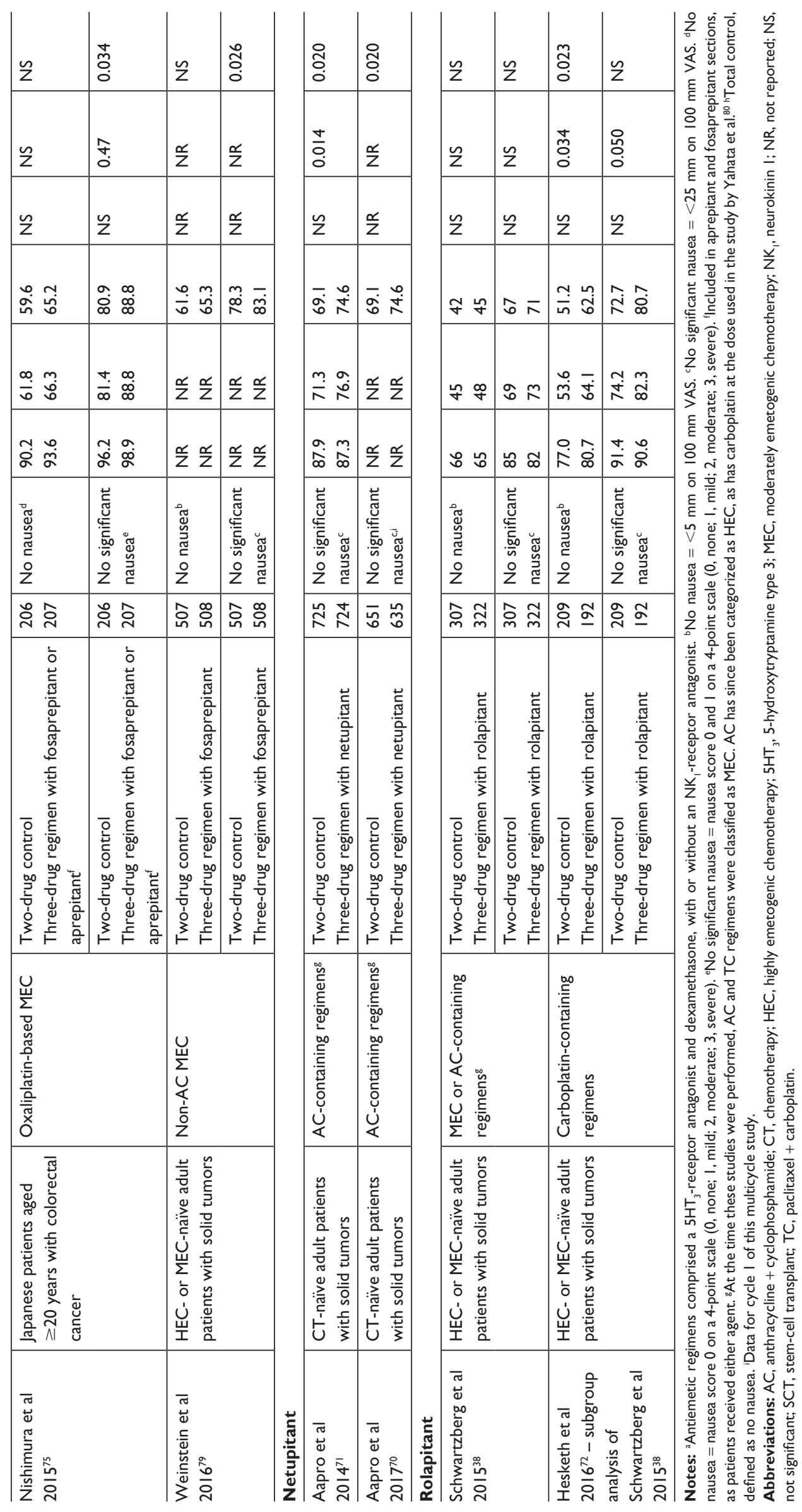




\section{Discussion}

Adding an $\mathrm{NK}_{1} \mathrm{RA}$ to an antiemetic regimen of a $5 \mathrm{HT}_{3}$ $\mathrm{RA}$ and dexamethasone significantly reduces the incidence of emesis and rescue medication (as measured by $\mathrm{CR}$ ) in patients at risk of CINV relative to dual therapy ${ }^{60,62,83}$ For patients receiving $\mathrm{HEC}$ or $\mathrm{AC}, \mathrm{NK}_{1}-\mathrm{RA}$-containing therapy (as triple therapy or with the addition of olanzapine) is now recommended for CINV prevention in all major antiemetic guidelines. ${ }^{16-19} \mathrm{NCCN}$ guidelines also include this three-drug regimen containing an $\mathrm{NK}_{1} \mathrm{RA}$ as a recommended option for patients receiving MEC, ${ }^{16}$ and ASCO guidelines recommend this three-drug regimen for patients receiving MEC that contains high-dose carboplatin. ${ }^{17}$ Some studies noted a lower $\mathrm{CR}$ in female patients than male patients receiving a three-drug antiemetic regimen containing an $\mathrm{NK}_{1} \mathrm{RA}$, consistent with female sex being a known risk factor for CINV; however, in all cases $\mathrm{CR}$ rates were higher in both male and female patients receiving an $\mathrm{NK}_{1}$-RA-containing three-drug antiemetic regimen compared with a two-drug regimen.

The efficacy of $\mathrm{NK}_{1}$ RAs in the control of nausea is less clear. Many studies did not measure nausea incidence or severity, and if they did, these were secondary or exploratory end points. Few studies to date have demonstrated a significant improvement in nausea control by adding an $\mathrm{NK}_{1} \mathrm{RA}$ to a two-drug antiemetic regimen, and those that did reported that only about half the patients treated with HEC experienced no nausea in the overall CINV phase. Therefore, there is still a need for more studies evaluating nausea end points and for better antiemetic regimens that improve nausea control.

Currently, $\mathrm{NK}_{1}$ RAs are available as both oral and IV formulations. The oral route is convenient, but nonadherence to treatment may negatively affect efficacy. Some patients with cancer cannot tolerate oral treatments, some patients may have difficulty swallowing because of mucositis, and oral drug bioavailability may be compromised by diarrhea or gastrointestinal ulceration. ${ }^{96}$ The IV formulations may be less convenient for patients and hospital staff, as they require patients to attend the clinic, ${ }^{96}$ but IV administration ensures treatment adherence and is suitable for patients with swallowing difficulties. Following the suspension of distribution of IV rolapitant, there are now three IV formulations of $\mathrm{NK}_{1}$ RAs: fosaprepitant, which contains polysorbate 80 and is associated with a high incidence of infusion-site and hypersensitivity reactions; ${ }^{32}$ an IV aprepitant formulation (HTX019) that is free of polysorbate 80 and other synthetic surfactants, and appears to have an improved tolerability profile; ${ }^{33,85}$ and IV NEPA, free of surfactant emulsifiers and solubility enhancers. ${ }^{29}$
Among the oral agents, rolapitant has the longest $t_{1 / 2}$ and requires only a single dose to be administered prior to chemotherapy. ${ }^{31}$ The oral and IV NEPA fixed combinations are also administered only once before chemotherapy, whereas additional doses of oral aprepitant are required on days 2-3 to prevent delayed CINV. ${ }^{29,30}$ However, the long $t_{1 / 2}$ of oral rolapitant appears to offer no clinical advantage: an indirect meta-analysis of $\mathrm{NK}_{1}$ RAs suggested that oral rolapitant was the least effective available agent in this class. ${ }^{60}$ All NK 1 RAs may be associated with potential drug interactions..$^{29-33}$ Those that are CYP3A4 substrates (aprepitant, fosaprepitant, and NEPA) should be given with a lower dose of dexamethasone on treatment day $1(12 \mathrm{mg})$ than the dose used with oral rolapitant $(20 \mathrm{mg}) .{ }^{16}$ When deciding which $\mathrm{NK}_{1}$ RA to use, physicians should consider the formulation, indication, pharmacology, efficacy, and safety of these agents, as well as any concomitant medications. It has been suggested that individualized antiemetic therapy, taking into account both treatment-related and patient-related risk factors, may be preferable to consensus guidelines, and patient-level CINV-predictive models have been proposed. ${ }^{97}$ In addition, NCCN guidelines recognize that the ultimate clinical decision on an appropriate antiemetic regimen may depend on the individual patient's situation and risk factors. ${ }^{16}$

Despite their clear benefits and recommendations in antiemetic guidelines, $\mathrm{NK}_{1}$ RAs are underutilized in clinical practice. Some institutions may limit the use of more expensive branded antiemetics by asking physicians to use a $5 \mathrm{HT}_{3}$ $\mathrm{RA}$ and dexamethasone in the first cycle, then add an $\mathrm{NK}_{1}$ RA in later cycles if the patient experiences CINV in cycle 1. This practice is inconsistent with antiemetic guidelines for patients receiving HEC (and many receiving MEC), and ignores the fact that the patient's first experience with chemotherapy is most crucial for CINV prevention. ${ }^{20}$ Patients whose CINV is controlled in the first cycle are more likely to do well in subsequent cycles, whereas patients who experience CINV during cycle 1 are more likely to develop refractory or anticipatory CINV..$^{73,98}$ Patients who do not achieve complete CINV control have poor quality of life, incur greater costs, and use more health-care resources. ${ }^{8,90,99}$ One option that has been considered is the use of olanzapine instead of an $\mathrm{NK}_{1}$ $\mathrm{RA}$ in combination with a $5 \mathrm{HT}_{3} \mathrm{RA}$ and dexamethasone. A randomized Phase III trial of olanzapine compared with oral aprepitant, both in combination with IV palonosetron and dexamethasone, in patients receiving cisplatin-based or AC-based HEC found no significant difference in CR rates between the two regimens, ${ }^{100}$ but there was a significant 
improvement in the control of nausea with olanzapine. In a meta-analysis of ten randomized controlled trials, olanzapine was more effective than oral aprepitant in the acute phase of CINV, but comparable in the delayed phase. ${ }^{101}$ A metaanalysis of 43 trials reported that an olanzapine-based triplet regimen improved nausea control, but was similar in CR to an $\mathrm{NK}_{1}$-triplet regimen. ${ }^{102}$ There are strong economic and clinical arguments for the use of guideline-recommended antiemetic protocols that include an $\mathrm{NK}_{1} \mathrm{RA}$ in addition to a $5 \mathrm{HT}_{3} \mathrm{RA}$ and dexamethasone (with or without olanzapine) during the first and subsequent chemotherapy cycles. This is especially important as hospitals transition to reimbursement for quality care rather than fees for service, and oncologists will be encouraged to keep patients out of the emergency department and hospital.

In conclusion, this review of published data with $\mathrm{NK}_{1}$ RAs highlights the efficacy of these agents in controlling emesis and rescue-medication use as part of three-drug or four-drug regimens, and the importance of patients receiving prophylactic regimens that comply with antiemetic guideline recommendations. For nausea control, the incremental benefit of using an $\mathrm{NK}_{1} \mathrm{RA}$ is less clear, so this remains an area for future research. While caution is needed in making cross-study comparisons, the available data suggest that the pharmacological differences between the $\mathrm{NK}_{1}-\mathrm{RA}$ inhibitors, specifically the longer $t_{1 / 2}$ of oral rolapitant, do not translate into enhanced clinical benefit, particularly within the HEC setting. Newer agents may offer key advantages in terms of better nausea control, tolerability, formulation options, and therapeutic plasma levels in the acute phase of CINV than the existing agents, and offer clinicians more opportunities to maximize the benefits of this important class of antiemetics.

\section{Author contribution}

LSS and RMN designed the systematic review, were responsible for the writing and critical revisions of the manuscript, read and approved the final manuscript, and agree to be accountable for all aspects of the work.

\section{Acknowledgment}

Medical writing assistance was provided by Yvonne Yarker, $\mathrm{PhD}$ and Nirzari Parikh, PhD of SciStrategy Communications and funded by Heron Therapeutics Inc.

\section{Disclosure}

LSS has had consulting/advisory relationships with Eisai, Helsinn, Merck, and Tesaro, and has received research funding from Helsinn. RMN has had a consulting/advisory relationship with Heron Therapeutics.

\section{References}

1. Grassi L, Berardi MA, et al; IOR-IRST Psycho-Oncology and UniFE Psychiatry Co-Authors. Role of psychosocial variables on chemotherapy-induced nausea and vomiting and health-related quality of life among cancer patients: a European study. Psychother Psychosom. 2015;84(6):339-347.

2. Salihah N, Mazlan N, Lua PL. Chemotherapy-induced nausea and vomiting: exploring patients' subjective experience. $J$ Multidiscip Healthc. 2016;9:145-151.

3. Haiderali A, Menditto L, Good M, Teitelbaum A, Wegner J. Impact on daily functioning and indirect/direct costs associated with chemotherapy-induced nausea and vomiting (CINV) in a US population. Support Care Cancer. 2011;19(6):843-851.

4. Hilarius DL, Kloeg PH, van der Wall E, van den Heuvel JJG, Gundy CM, Aaronson NK. Chemotherapy-induced nausea and vomiting in daily clinical practice: a community hospital-based study. Support Care Cancer. 2012;20(1):107-117.

5. Ballatori E, Roila F, Ruggeri B, et al. The impact of chemotherapyinduced nausea and vomiting on health-related quality of life. Support Care Cancer. 2007;15(2):179-185.

6. Farrell C, Brearley SG, Pilling M, Molassiotis A. The impact of chemotherapy-related nausea on patients' nutritional status, psychological distress and quality of life. Support Care Cancer. 2013;21(1):59-66.

7. Fernández-Ortega P, Caloto MT, Chirveches E, et al. Chemotherapyinduced nausea and vomiting in clinical practice: impact on patients' quality of life. Support Care Cancer. 2012;20(12):3141-3148.

8. Sommariva S, Pongiglione B, Tarricone R. Impact of chemotherapy-induced nausea and vomiting on health-related quality of life and resource utilization: a systematic review. Crit Rev Oncol Hematol. 2016;99:13-36.

9. Craver C, Gayle J, Balu S, Buchner D. Clinical and economic burden of chemotherapy-induced nausea and vomiting among patients with cancer in a hospital outpatient setting in the United States. J Med Econ. 2011; 14(1):87-98.

10. Kreys ED, Kim TY, Delgado A, Koeller JM. Impact of cancer supportive care pathways compliance on emergency department visits and hospitalizations. J Oncol Pract. 2014;10(3):168-173.

11. Kim H-K, Hsieh R, Chan A, et al. Impact of CINV in earlier cycles on CINV and chemotherapy regimen modification in subsequent cycles in Asia Pacific clinical practice. Support Care Cancer. 2015;23(1):293-300.

12. du Bois A, Meerpohl HG, Kommoss FGM, Pfleiderer A, Vach W, Fenzl E. Course, patterns, and risk-factors for chemotherapy-induced emesis in cisplatin-pretreated patients: a study with ondansetron. Eur J Cancer. 1992;28(2-3):450-457.

13. Navari RM. 5-HT3 receptors as important mediators of nausea and vomiting due to chemotherapy. Biochim Biophys Acta. 1848;2015(10 Pt B): 2738-2746.

14. Roscoe JA, Morrow GR, Colagiuri B, et al. Insight in the prediction of chemotherapy-induced nausea. Support Care Cancer. 2010;18(7):869-876.

15. Di Mattei VE, Carnelli L, Carrara L, et al. Chemotherapy-induced nausea and vomiting in women with gynecological cancer: a preliminary single-center study investigating medical and psychosocial risk factors. Cancer Nurs. 2016;39(6):E52-E59.

16. National Comprehensive Cancer Network. NCCN Clinical Practice Guidelines in Oncology: Antiemesis - Version 3.2018. Available from: www.nccn.org/patients. Accessed June 11, 2018.

17. Hesketh PJ, Kris MG, Basch E, et al. Antiemetics: American Society of Clinical Oncology Clinical Practice Guideline Update. J Clin Oncol. 2017;35(28):3240-3261.

18. Herrstedt J, Roila F, Warr D, et al. 2016 Updated MASCC/ESMO consensus recommendations: prevention of nausea and vomiting following high emetic risk chemotherapy. Support Care Cancer. 2017; 25(1):277-288. 
19. Roila F, Warr D, Hesketh PJ, et al. 2016 updated MASCC/ESMO consensus recommendations: prevention of nausea and vomiting following moderately emetogenic chemotherapy. Support Care Cancer. 2017;25(1):289-294.

20. Hesketh PJ. Chemotherapy-induced nausea and vomiting. $N$ Engl $J$ Med. 2008;358(23):2482-2494.

21. Abunahlah N, Sancar M, Dane F, Özyavuz MK. Impact of adherence to antiemetic guidelines on the incidence of chemotherapy-induced nausea and vomiting and quality of life. Int J Clin Pharm. 2016;38(6):1464-1476.

22. Caracuel F, Muñoz N, Baños U, Ramirez G. Adherence to antiemetic guidelines and control of chemotherapy-induced nausea and vomiting (CINV) in a large hospital. J Oncol Pharm Pract. 2015; 21(3):163-169.

23. Gilmore JW, Peacock NW, Gu A, et al. Antiemetic guideline consistency and incidence of chemotherapy-induced nausea and vomiting in US community oncology practice: INSPIRE Study. J Oncol Pract. 2014; 10(1):68-74.

24. Aapro M, Molassiotis A, Dicato M, et al. The effect of guidelineconsistent antiemetic therapy on chemotherapy-induced nausea and vomiting (CINV): the Pan European Emesis Registry (PEER). Ann Oncol. 2012;23(8):1986-1992.

25. De Laurentiis M, Bonfadini C, Lorusso V, et al. Incidence of nausea and vomiting in breast cancer patients treated with anthracycline plus cyclophosphamide-based chemotherapy regimens in Italy: NAVY observational study. Support Care Cancer. Epub 2018 Jun 25.

26. Hsieh RK, Chan A, Kim H-K, et al. Baseline patient characteristics, incidence of CINV, and physician perception of CINV incidence following moderately and highly emetogenic chemotherapy in Asia Pacific countries. Support Care Cancer. 2015;23(1):263-272.

27. Salsman JM, Grunberg SM, Beaumont JL, et al. Communicating about chemotherapy-induced nausea and vomiting: a comparison of patient and provider perspectives. J Natl Compr Canc Netw. 2012;10(2):149-157.

28. Rojas C, Raje M, Tsukamoto T, Slusher BS. Molecular mechanisms of $5-\mathrm{HT}_{3}$ and $\mathrm{NK}_{1}$ receptor antagonists in prevention of emesis. Eur J Pharmacol. 2014;722:26-37.

29. Aknyzeo (netupitant and palonosetron) capsules, for oral use and (fosnetupitant and palonosetron) for injection [prescribing information]. Islen, NJ: Helsinn Therapeutics; April 2018.

30. Emend (aprepitant) capsules, for oral use and Emend (aprepitant) for oral suspension [prescribing information]. Whitehouse Station, NJ: Merck \& Co; May 2017.

31. Varubi (rolapitant) tablets, for oral use and Varubi (rolapitant) injectable emulsion, for intravenous use [prescribing information]. Waltham, MA: Tesaro Inc; March 2018.

32. Emend (fosaprepitant) for injection, for intravenous use [prescribing information]. Whitehouse Station, NJ: Merck \& Co; April 2018.

33. Cinvanti ${ }^{\mathrm{TM}}$ (aprepitant) injectable emulsion, for intravenous use. San Diego, CA: Heron Therapeutics; Nov 2017.

34. Helsinn Group announces the FDA approval of the IV formulation of Akynzeo (fosnetupitant/palonosetron) in the United States [press release]; April 20, 2018. Available from: https://www.helsinn.com/ news-and-events/helsinn-group-announces-the-fda-approval-of-theiv-formulation-of-akynzeo-fosnetupitantpalonosetron-in-the-unitedstates/. Accessed May 7, 2018.

35. Wang $X$, Zhang Z-Y, Powers D, et al. Bioequivalence of intravenous and oral rolapitant: results from a randomized, open-label pivotal study. J Clin Pharmacol. 2017;57(12):1600-1606.

36. Rapoport B, Chua D, Poma A, Arora S, Wang Y, Fein LE. Study of rolapitant, a novel, long-acting, NK-1 receptor antagonist, for the prevention of chemotherapy-induced nausea and vomiting (CINV) due to highly emetogenic chemotherapy (HEC). Support Care Cancer. 2015;23(11):3281-3288.

37. Rapoport BL, Chasen MR, Gridelli C, et al. Safety and efficacy of rolapitant for prevention of chemotherapy-induced nausea and vomiting after administration of cisplatin-based highly emetogenic chemotherapy in patients with cancer: two randomised, active-controlled, double-blind, phase 3 trials. Lancet Oncol. 2015;16(9):1079-1089.
38. Schwartzberg LS, Modiano MR, Rapoport BL, et al. Safety and efficacy of rolapitant for prevention of chemotherapy-induced nausea and vomiting after administration of moderately emetogenic chemotherapy or anthracycline and cyclophosphamide regimens in patients with cancer: a randomised, active-controlled, double-blind, phase 3 trial. Lancet Oncol. 2015;16(9):1071-1078.

39. Spinelli T, Calcagnile S, Giuliano C, et al. Netupitant PET imaging and ADME studies in humans. J Clin Pharmacol. 2014;54(1):97-108.

40. van Laere K, de Hoon J, Bormans G, et al. Equivalent dynamic human brain NK1-receptor occupancy following single-dose i.v. fosaprepitant vs. oral aprepitant as assessed by PET imaging. Clin Pharmacol Ther. 2012;92(2):243-250

41. Wang X, Zhang ZY, Powers D, Wang J, Lu S, Kansra V. Rolapitant absolute bioavailability and PET imaging studies in healthy adult volunteers. Clin Pharmacol Ther. 2017;102(2): 332-339.

42. Wang X, Zhang Z-Y, Arora S, et al. Effects of rolapitant administered intravenously or orally on the pharmacokinetics of digoxin (P-glycoprotein substrate) and sulfasalazine (breast cancer resistance protein substrate) in healthy volunteers. J Clin Pharmacol. 2018; 58(2):202-211.

43. Chawla SP, Grunberg SM, Gralla RJ, et al. Establishing the dose of the oral NK1 antagonist aprepitant for the prevention of chemotherapyinduced nausea and vomiting. Cancer. 2003;97(9):2290-2300.

44. Gralla RJ, de Wit R, Herrstedt J, et al. Antiemetic efficacy of the neurokinin-1 antagonist, aprepitant, plus a $5 \mathrm{HT}_{3}$ antagonist and a corticosteroid in patients receiving anthracyclines or cyclophosphamide in addition to high-dose cisplatin: analysis of combined data from two phase III randomized clinical trials. Cancer. 2005;104(4): 864-868.

45. Herrington JD, Jaskiewicz AD, Song J. Randomized, placebocontrolled, pilot study evaluating aprepitant single dose plus palonosetron and dexamethasone for the prevention of acute and delayed chemotherapy-induced nausea and vomiting. Cancer. 2008;112(9): 2080-2087.

46. Hesketh PJ, Grunberg SM, Gralla RJ, et al. The oral neurokinin-1 antagonist aprepitant for the prevention of chemotherapy-induced nausea and vomiting: a multinational, randomized, double-blind, placebo-controlled trial in patients receiving high-dose cisplatin - the Aprepitant Protocol 052 Study Group. J Clin Oncol. 2003;21(22): 4112-4119.

47. Hesketh PJ, Rossi G, Rizzi G, et al. Efficacy and safety of NEPA, an oral combination of netupitant and palonosetron, for prevention of chemotherapy-induced nausea and vomiting following highly emetogenic chemotherapy: a randomized dose-ranging pivotal study. Ann Oncol. 2014;25(7):1340-1346.

48. Hu Z, Cheng Y, Zhang H, et al. Aprepitant triple therapy for the prevention of chemotherapy-induced nausea and vomiting following high-dose cisplatin in Chinese patients: a randomized, double-blind, placebo-controlled phase III trial. Support Care Cancer. 2014;22(4): 979-987.

49. Ito Y, Karayama M, Inui N, et al. Aprepitant in patients with advanced non-small-cell lung cancer receiving carboplatin-based chemotherapy. Lung Cancer. 2014;84(3):259-264.

50. Kusagaya H, Inui N, Karayama M, et al. Evaluation of palonosetron and dexamethasone with or without aprepitant to prevent carboplatininduced nausea and vomiting in patients with advanced non-small-cell lung cancer. Lung Cancer. 2015;90(3):410-416.

51. Poli-Bigelli S, Rodrigues-Pereira J, Carides AD, et al. Addition of the neurokinin 1 receptor antagonist aprepitant to standard antiemetic therapy improves control of chemotherapy-induced nausea and vomiting. Results from a randomized, double-blind, placebo-controlled trial in Latin America. Cancer. 2003;97(12):3090-3098.

52. Ruhlmann CH, Christensen TB, Dohn LH, et al. Efficacy and safety of fosaprepitant for the prevention of nausea and emesis during 5 weeks of chemoradiotherapy for cervical cancer (the GAND-emesis study): a multinational, randomised, placebo-controlled, double-blind, phase 3 trial. Lancet Oncol. 2016;17(4):509-518. 
53. Saito H, Yoshizawa H, Yoshimori K, et al. Efficacy and safety of singledose fosaprepitant in the prevention of chemotherapy-induced nausea and vomiting in patients receiving high-dose cisplatin: a multicentre, randomised, double-blind, placebo-controlled phase 3 trial. Ann Oncol. 2013;24(4):1067-1073.

54. Schmoll HJ, Aapro MS, Poli-Bigelli S, et al. Comparison of an aprepitant regimen with a multiple-day ondansetron regimen, both with dexamethasone, for antiemetic efficacy in high-dose cisplatin treatment. Ann Oncol. 2006;17(6):1000-1006.

55. Takahashi T, Hoshi E, Takagi M, Katsumata N, Kawahara M, Eguchi K. Multicenter, phase II, placebo-controlled, double-blind, randomized study of aprepitant in Japanese patients receiving high-dose cisplatin. Cancer Sci. 2010;101(11):2455-2461.

56. Zhang L, Lu S, Feng J, et al. A randomized phase III study evaluating the efficacy of single-dose NEPA, a fixed antiemetic combination of netupitant and palonosetron, versus an aprepitant regimen for prevention of chemotherapy-induced nausea and vomiting (CINV) in patients receiving highly emetogenic chemotherapy (HEC). Ann Oncol. 2018;29(2):452-458.

57. Di Maio M, Baratelli C, Bironzo P, et al. Efficacy of neurokinin-1 receptor antagonists in the prevention of chemotherapy-induced nausea and vomiting in patients receiving carboplatin-based chemotherapy: a systematic review and meta-analysis. Crit Rev Oncol Hematol. 2018; 124:21-28

58. Warr D. Prognostic factors for chemotherapy induced nausea and vomiting. Eur J Pharmacol. 2014;722:192-196.

59. Hesketh PJ, Aapro M, Street JC, Carides AD. Evaluation of risk factors predictive of nausea and vomiting with current standard-of-care antiemetic treatment: analysis of two phase III trials of aprepitant in patients receiving cisplatin-based chemotherapy. Support Care Cancer. 2010;18(9):1171-1177.

60. Abdel-Rahman O. Neurokinin-1 inhibitors in the prevention of nausea and vomiting from highly emetogenic chemotherapy: a network metaanalysis. Ther Adv Med Oncol. 2016;8(5):396-406.

61. Jordan K, Warr DG, Hinke A, Sun L, Hesketh PJ. Defining the efficacy of neurokinin-1 receptor antagonists in controlling chemotherapyinduced nausea and vomiting in different emetogenic settings - a meta-analysis. Support Care Cancer. 2016;24(5):1941-1954.

62. Yuan D-M, Li Q, Zhang Q, et al. Efficacy and safety of neurokinin-1 receptor antagonists for prevention of chemotherapy-induced nausea and vomiting: systematic review and meta-analysis of randomized controlled trials. Asian Pac J Cancer Prev. 2016;17(4): 1661-1675.

63. Olver I, Molassiotis A, Aapro M, Herrstedt J, Grunberg S, Morrow G. Antiemetic research: future directions. Support Care Cancer. 2011; 19(S1):49-55.

64. Olver IN. Antiemetic study methodology: recommendations for future studies. Oncology. 1996;53(1):96-101.

65. Maru A, Gangadharan VP, Mohapatra RK, Carides AD, Desai CJ. A Phase 3, randomized, double-blind study of single-dose fosaprepitant for prevention of cisplatin-induced nausea and vomiting: results of an Indian population subanalysis. Indian J Cancer. 2013; 50(4):285-291.

66. Gralla RJ, Bosnjak SM, Hontsa A, et al. A phase III study evaluating the safety and efficacy of NEPA, a fixed-dose combination of netupitant and palonosetron, for prevention of chemotherapy-induced nausea and vomiting over repeated cycles of chemotherapy. Ann Oncol. 2014;25(7):1333-1339.

67. Jordan K, Gralla R, Rizzi G, Kashef K. Efficacy benefit of an NK1 receptor antagonist (NK1RA) in patients receiving carboplatin: supportive evidence with NEPA (a fixed combination of the NK1 RA, netupitant, and palonosetron) and aprepitant regimens. Support Care Cancer. 2016;24(11):4617-4625.

68. Mizukami N, Yamauchi M, Koike K, et al. Olanzapine for the prevention of chemotherapy-induced nausea and vomiting in patients receiving highly or moderately emetogenic chemotherapy: a randomized, double-blind, placebo-controlled study. J Pain Symptom Manage. 2014; 47(3):542-550.
69. Navari RM, Qin R, Ruddy KJ, et al. Olanzapine for the prevention of chemotherapy-induced nausea and vomiting. $N$ Engl J Med. 2016;375(2):134-142.

70. Aapro M, Karthaus M, Schwartzberg L, et al. NEPA, a fixed oral combination of netupitant and palonosetron, improves control of chemotherapy-induced nausea and vomiting (CINV) over multiple cycles of chemotherapy: results of a randomized, double-blind, phase 3 trial versus oral palonosetron. Support Care Cancer. 2017;25(4):1127-1135.

71. Aapro M, Rugo H, Rossi G, et al. A randomized phase III study evaluating the efficacy and safety of NEPA, a fixed-dose combination of netupitant and palonosetron, for prevention of chemotherapy-induced nausea and vomiting following moderately emetogenic chemotherapy. Ann Oncol. 2014;25(7):1328-1333.

72. Hesketh PJ, Schnadig ID, Schwartzberg LS, et al. Efficacy of the neurokinin-1 receptor antagonist rolapitant in preventing nausea and vomiting in patients receiving carboplatin-based chemotherapy. Cancer. 2016;122(15):2418-2425.

73. Kim JE, Jang J-S, Kim J-W, et al. Efficacy and safety of aprepitant for the prevention of chemotherapy-induced nausea and vomiting during the first cycle of moderately emetogenic chemotherapy in Korean patients with a broad range of tumor types. Support Care Cancer. 2017; 25(3):801-809.

74. Kitayama H, Tsuji Y, Sugiyama J, Doi A, Kondo T, Hirayama M. Efficacy of palonosetron and 1-day dexamethasone in moderately emetogenic chemotherapy compared with fosaprepitant, granisetron, and dexamethasone: a prospective randomized crossover study. Int $J$ Clin Oncol. 2015;20(6):1051-1056.

75. Nishimura J, Satoh T, Fukunaga M, et al. Combination antiemetic therapy with aprepitant/fosaprepitant in patients with colorectal cancer receiving oxaliplatin-based chemotherapy (SENRI trial): a multicentre, randomised, controlled phase 3 trial. Eur J Cancer. 2015; 51(10):1274-1282.

76. Rapoport BL, Jordan K, Boice JA, et al. Aprepitant for the prevention of chemotherapy-induced nausea and vomiting associated with a broad range of moderately emetogenic chemotherapies and tumor types: a randomized, double-blind study. Support Care Cancer. 2010; 18(4):423-431.

77. Schmitt T, Goldschmidt H, Neben K, et al. Aprepitant, granisetron, and dexamethasone for prevention of chemotherapy-induced nausea and vomiting after high-dose melphalan in autologous transplantation for multiple myeloma: results of a randomized, placebo-controlled phase III trial. J Clin Oncol. 2014;32(30):3413-3420.

78. Warr DG, Hesketh PJ, Gralla RJ, et al. Efficacy and tolerability of aprepitant for the prevention of chemotherapy-induced nausea and vomiting in patients with breast cancer after moderately emetogenic chemotherapy. J Clin Oncol. 2005;23(12):2822-2830.

79. Weinstein C, Jordan K, Green SA, et al. Single-dose fosaprepitant for the prevention of chemotherapy-induced nausea and vomiting associated with moderately emetogenic chemotherapy: results of a randomized, double-blind phase III trial. Ann Oncol. 2016;27(1):172-178.

80. Yahata H, Kobayashi H, Sonoda K, et al. Efficacy of aprepitant for the prevention of chemotherapy-induced nausea and vomiting with a moderately emetogenic chemotherapy regimen: a multicenter, placebocontrolled, double-blind, randomized study in patients with gynecologic cancer receiving paclitaxel and carboplatin. Int J Clin Oncol. 2016; 21(3):491-497.

81. Yeo W, Mo FKF, Suen JJS, et al. A randomized study of aprepitant, ondansetron and dexamethasone for chemotherapy-induced nausea and vomiting in Chinese breast cancer patients receiving moderately emetogenic chemotherapy. Breast Cancer Res Treat. 2009;113(3):529-535.

82. Tanioka M, Kitao A, Matsumoto K, et al. A randomised, placebocontrolled, double-blind study of aprepitant in nondrinking women younger than 70 years receiving moderately emetogenic chemotherapy. Br J Cancer. 2013;109(4):859-865.

83. Jordan K, Blättermann L, Hinke A, Müller-Tidow C, Jahn F. Is the addition of a neurokinin-1 receptor antagonist beneficial in moderately emetogenic chemotherapy? A systematic review and meta-analysis. Support Care Cancer. 2018;26(1):21-32. 
84. Sekine I, Segawa Y, Kubota K, Saeki T. Risk factors of chemotherapyinduced nausea and vomiting: index for personalized antiemetic prophylaxis. Cancer Sci. 2013;104(6):711-717.

85. Ottoboni T, Keller MR, Cravets M, Clendeninn N, Quart B. Bioequivalence of HTX-019 (aprepitant IV) and fosaprepitant in healthy subjects: a phase 1, open-label, randomized, 2-way crossover evaluation. Drug Des Devel Ther. 2018;12:429-435.

86. Ottoboni T, Lauw M, Keller MR, et al. Safety of HTX-019 (intravenous aprepitant) and fosaprepitant in healthy subjects. Future Oncol. 2018; Epub 2018 Jun 6.

87. Navari RM. The safety of antiemetic medications for the prevention of chemotherapy-induced nausea and vomiting. Expert Opin Drug Saf. 2016;15(3):343-356.

88. Wu G, Yeung S, Chen F. Compatibility and stability of rolapitant injectable emulsion admixed with intravenous palonosetron hydrochloride. Int J Pharm Compd. 2017;21(1):76-82.

89. Wu G, Yeung S, Chen F. Compatibility and stability of rolapitant injectable emulsion admixed with intravenous palonosetron hydrochloride injection and dexamethasone sodium phosphate. Int J Pharm Compd. 2018;22(1):76-85.

90. Aapro M, Carides A, Rapoport BL, Schmoll HJ, Zhang L, Warr D. Aprepitant and fosaprepitant: a 10-year review of efficacy and safety. Oncologist. 2015;20(4):450-458.

91. Ten Tije AJ, Verweij J, Loos WJ, Sparreboom A. Pharmacological effects of formulation vehicles: implications for cancer chemotherapy. Clin Pharmacokinet. 2003;42(7):665-685.

92. van Zuylen L, Verweij J, Sparreboom A. Role of formulation vehicles in taxane pharmacology. Invest New Drugs. 2001;19(2):125-141.

93. Schwartzberg L, Andric Z, Kowalski D, Voisin D, Rizzi G, Karthaus M. Phase 3 safety evaluation of an intravenous formulation of NEPA, a novel fixed antiemetic combination of fosnetupitant and palonosetron. Ann Oncol. 2017;28(suppl 5):545.Abstract 1547PD.
94. Schwartzberg LS, Andric ZG, Kowalski D, Voisin D, Rizzi G, Karthaus M. Phase III safety evaluation of intravenous NEPA, a novel fixed antiemetic combination of fosnetupitant and palonosetron, over multiple cycles. J Clin Oncol. 2017;35(31 suppl):Abstract 122.

95. Aapro MS, Walko CM. Aprepitant: drug-drug interactions in perspective. Ann Oncol. 2010;21(12):2316-2323.

96. Kraut L, Fauser AA. Anti-emetics for cancer chemotherapy-induced emesis: potential of alternative delivery systems. Drugs. 2001;61(11): 1553-1562.

97. Clemons M. Guidelines versus individualized care for the management of CINV. Support Care Cancer. 2018;27(suppl 5):11-17.

98. Molassiotis A, Lee PH, Burke TA, et al. Anticipatory nausea, risk factors, and its impact on chemotherapy-induced nausea and vomiting: results from the Pan European Emesis Registry Study. J Pain Symptom Manage. 2016;51(6):987-993.

99. Ihbe-Heffinger A, Ehlken B, Bernard R, et al. The impact of delayed chemotherapy-induced nausea and vomiting on patients, health resource utilization and costs in German cancer centers. Ann Oncol. 2004;15(3):526-536.

100. Navari RM, Gray SE, Kerr AC. Olanzapine versus aprepitant for the prevention of chemotherapy-induced nausea and vomiting: a randomized phase III trial. J Support Oncol. 2011;9(5):188-195.

101. Yang T, Liu Q, Lu M, Ma L, Zhou Y, Cui Y. Efficacy of olanzapine for the prophylaxis of chemotherapy-induced nausea and vomiting: a meta-analysis. Br J Clin Pharmacol. 2017;83(7):1369-1379.

102. Zhang Z, Zhang Y, Chen G, et al. Olanzapine-based triple regimens versus neurokinin-1 receptor antagonist-based triple regimens in preventing chemotherapy-induced nausea and vomiting associated with highly emetogenic chemotherapy: a network meta-analysis. Oncologist. 2018;23(5):603-616.
OncoTargets and Therapy

\section{Publish your work in this journal}

OncoTargets and Therapy is an international, peer-reviewed, open access journal focusing on the pathological basis of all cancers, potential targets for therapy and treatment protocols employed to improve the management of cancer patients. The journal also focuses on the impact of management programs and new therapeutic agents and protocols on

\section{Dovepress}

patient perspectives such as quality of life, adherence and satisfaction The manuscript management system is completely online and includes a very quick and fair peer-review system, which is all easy to use. Visit http://www.dovepress.com/testimonials.php to read real quotes from published authors. 